\title{
Mathematical Simulation of Sediment and Radionuclide Transport in Surface Waters
}

\author{
Annual Report \\ October 1978 - September 1979
}

Prepared by Y. Onishi, D. S. Trent

Pacific Northwest Laboratory

Operated by

Battelle Memorial Institute

Prepared for

U.S. Nuclear Regulatory

Commission 


\section{NOTICE}

This report was prepared as an account of work sponsored by an agency of the United States Government. Neither the United States Government nor any agency thereof, or any of their employees, makes any warranty, expressed or implied, or assumes any legal liability or responsibility for any third party's use, or the results of such use, of any information, apparatus product or process disclosed in this report, or represents that its use by such third party would not infringe privately owned rights.

U. S. Nuclear Regulatory Commission Washington, D. C. 20555

Printed copy price: \$4.00

$$
\text { and }
$$




\section{Mathematical Simulation of Sediment and Radionuclide Transport in Surface Waters}

Annual Report

October 1978 - September 1979

Manuscript Completed: September 1980

Date Published: Aprit 1981

Prepared by

Y. Onishi, D. S. Trent

Pacific Northwest Laboratory

Richland, WA 99352

\section{Prepared for}

Division of Safeguards, Fuel Cycle and Environmental Research

Office of Nuclear Regulatory Research

U.S. Nuclear Regulatory Commission

Washington, D.C. 20555

NRC FIN B2271 



\section{ABSTRACT}

The study objective of "The Mathematical Simulation of Sediment and Radionuclide Transport in Surface Waters" is to synthesize and test radionuclide transport models capable of realistically assessing radionuclide transport in various types of surface water bodies by including the sediment-radionuclide interactions. These interactions include radionuclide adsorption by sediment; desorption from sediment into water; and transport, deposition, and resuspension of sorbed radionuclides rontrolled by the sediment movements. During FY-1979, the modification of sediment and contaminant (radionuclide) transport mode1, FETRA, was completed to make it applicable to coastal waters. The model is an unsteady, two-dimensional (longitudinal and laterai) model that consists of three submodeis (for sediment, dissolved-contaminant, and particulatecontaminant transport), coupled to include the sediment-contaminant interactions. In estuaries, flow phenomena and consequent sediment and radionuclide migration are often three-dimensional in nature mainly because of nonuniform channel cross-sections, salinity intrusion, and lateral-flow circulation. Thus, an unsteady, three-dimensional radionuclide transport model for estuaries is also being synthesized by combining and modifying a PNL unsteady hydro thermal model and FETRA. These two radionuclide transport models for coastal waters and estuaries will be applied to actual sites to examine the validity of the codes. 
. 
SUMMARY

The objective of this study is to synthesize and test radionuclide transport models capable of realistically assessing radionuclide migration and fate in oceans (coastal waters), estuaries, and lakes, by including the sedimentradionuclide interactions. These interactions include radionuclide adsorption by sediment; desorptin from sediment into water; and transport, deposition, and resuspension of sorbed radionuclides controlled by the sediment movement.

During Fy-1979, the modification of sediment and contaminant transport model, FETRA, was completed, making it applicable to coastal waters. The primary modification made was to include a mechanism to suspend sediment caused by wave action. The model is an unsteady, two-dimensional (longitudinal and lateral) model which consists of the following three submodels coupled to include the sediment-radionuclide interactions:

1. a sediment transport submodel

2. a dissolved-contaminant transport submodel

3. a particulate-contaminant (those adsorbed by sediment) transport submode1.

In preliminary tests, FETRA was used to caiculate noncohesive (sand) sediment loads caused by waves in offshore and surf zones, to examine the computational schemes of the sediment-wave interactions.

For many estuaries, flow phenomena, and consequent sediment and radionuclide migration are three-dimensional in nature, mainly because of nonuniform channel cross sections, salinity intrusion, and lateral-flow circulation. Thus, an unsteady, three-dimensional radionuclide transport model for estuaries is being synthesized by combining and modifying a PNL unsteady, three-dimensional hydro-thermal model and FETRA.

The model will fully couple tne following submodels:

1. a hydrodynamic submodel

2. a water-temperature submode 1 
3. a salinity submode?

4. a sediment-transport submodel

5. a dissolved-contaminant transport submodel

6. a particulate-contaminant transport submodel.

Some preliminary testing of the model demonstrated that it can handle a large aspect ratio (ratio of length to width to depth) for each computational cell (say, 10,000:300:1). Comparison of this model with the Leendertse model (Leendertse, Alexander and Liu 1973), of computed flows induced by wind in a rectangular basin, indicated reasonable agreement between the two.

The next step is to apply these two models to actual coastal (the Irish Sea) and estuarine (the Hudson River estuary) sites to examine the validity of the models. 


\section{CONTENTS}

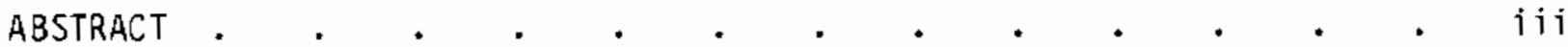

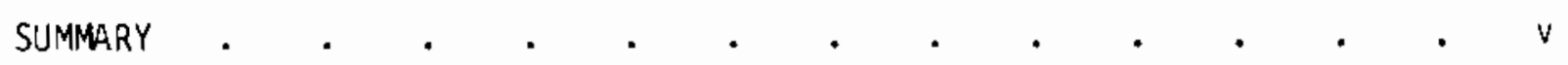

1.0 INTRODUCTION

2.0 SYNTHESIS OF RADIONUCLIDE TRANSPORT MODEL. FOR COASTAL WATERS. . 2

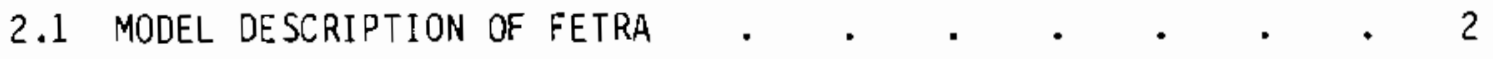

2.1.1 Sediment Transport Submodel . . . . . . 2

2.1.2 Dissolved-Contaminant Transport Model . . . . 19

2.1.3 Particulate-Contaminant Transport Model . . . 23

2.l.4 Finite-Element Method . . . . . . . 26

2.2 EXAMINATION OF BASIC COMPUTATIONAL SCHEME.$\quad \cdot \quad \cdot \quad \cdot 26$

2.3 SOME COMPUTATIONS OF SEDIMENT TRANSPORT CAPACITY UNDER

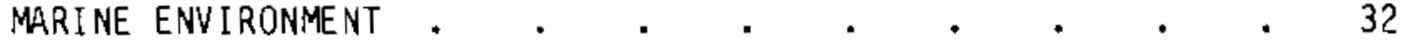

3.0 TRANSPORT OF SEDIMENT AND RADIONUCLIDES IN ESTUARIES . • • • 36

3.1 DESCRIPTION OF THREE-DIMENSIONAL MODEL FOR OISTRIBUTIONS OF

FL.OW, TEMPERATURE, SALINITY, SEDIMENT, AND RADIONUCLIDES · 36

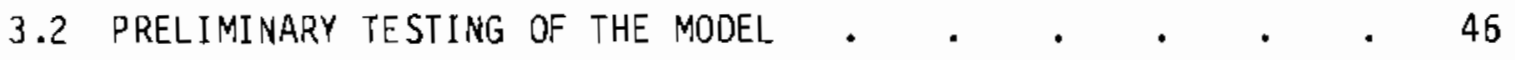

3.3 MODEL APPLICATION $. \quad . \quad . \quad . \quad . \quad . \quad . \quad . \quad . \quad 50$

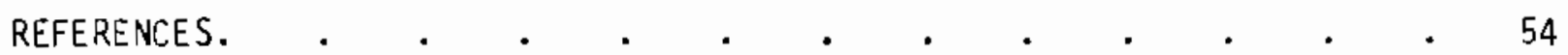

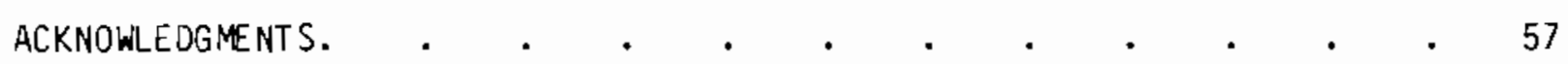





\section{FIGURES}

1 Comparison of Numerical Solution with Analytical Solution of of One-Dimensional Steady Advection-Diffusion Equation with

a Decay Term . . . . . . . . . . . 28

2 Convergence of Unsteady-State One-Dimensional Diffusion Equation to Steady-State Solution. $. \quad . \quad . \quad . \quad . \quad . \quad$. 29

3 Comparison of FETRA and Analytical Solutions to the Unsteady Advection-Diffusion Equation . . . . . . . . . . 30

4 Comparison of Numerical Solution with Analytical Solution to Two-Dimensional Diffusion Equation . . . . . . . . 32

5 Calculated Sediment Load Due to Wind-Induced Waves in Marine Environment . . . . . . . . . . . . . . 34

6 Longshore Transport Rate as a Function of Breaker Height and Breaker Angle, Together with Sediment Load Computed by the

7 Rectangular Waterbody Used for the Examination of the Aspect Ratio . . . . . . . . . . . . . 47

8 Variation of Longitudinal (Downstream) Velocities Along $Z=5.5 \mathrm{ft}$

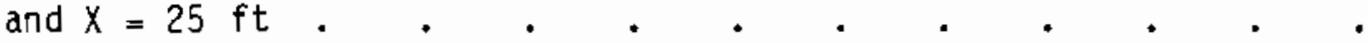

$g$ Vertical Variation of Longitudinal (Downstream) Velocities Along $X=25 \mathrm{ft}$

10 Variation of Longitudinal (Downstream) Velocities Along $Z=5.5 \mathrm{ft}$ and $X=750 \mathrm{ft}$.

11 Vertical Variation of Longitudinal (Downstream) Velocities Along $X=750 \mathrm{ft}$

12 Water Body Used for the Wind-Driven Circulation Computation . .

13 Predicted Velocity Distributions in a Cross-Section and in Seven Horizontal Planes in a Hind-Driven Rectangular Basin at 375 Second of the Computation.

14 Velocity Distribution in a Cross-Section and in Seven Horizontal Layers of a Wind-Oriven Rectangular Basin at 375 Second of the Computation by the Leendertse's Model (1973). 
$\underline{\text { TABLES }}$

1 Stability Criteria . . . . . . . . . . 31

2 Test Conditions of Sand Transport Capacities . . . . . 33

3 Input Parameters and Computed Sediment Transport Capacity

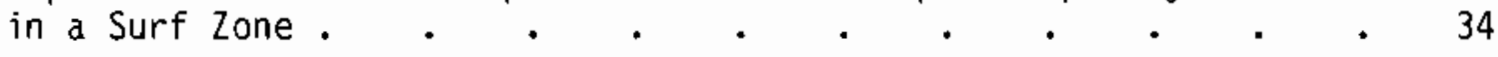




\subsection{INTRODUCTION}

Mathematical models, coordinated with data-sampling programs, can be very useful tools in assessing the radionuclide inigration and fate in various types of surface waters (e.g., rivers, estuaries, oceans, and lakes). To obtain accurate predictions of radionuclide distributions, models must include major transport and fate mechanisms. These mecnanisins include: 1) advection and dispersion of radionuclides by flow and sediment; 2) adsorption and desorption; 3) radionuclide decay and cnain reaction; and 4) radionuclide contrioutions from point and nonpoint sources, and subsequent mixing. Most of the currentiy available models, nowever, do not include sediment-radionuclide interactions (Daily and Harleman 1972; Baca et al. 1973; Leendertse 1970; Yotsukura and Sayre 1976; Onishi et al. 1980a).

The purpose of this study is 1) to deveiop radionuclide transport models for various types of surface water bodies by including sediment-radionuclide interactions, and 2) to apply these models to actual sites to examine the validity of the models. In this report, synthesis of radianuclide models for coastal waters and estuaries are presented. 


\subsection{SYNTHESIS OF RADIONUCLIOE TRANSPORT MOOEL FOR COASTAL WATERS}

During FY-1979, modification of the sediment and contaminant transport model, FETRA, was completed to make it applicable to coastal waters. A topical report for this task, entitled "Modified Finite Element Transport Model, FETRA, for Sediment and Radionuclide Migration in Open Coastal Waters," Cnishi, Arnold and Mayer 1979), was submitted to the U.S. Nuclear Regulatory Commission in August 1979. For the completeness of this annual report, the modified version of FETRA is described here.

\subsection{MDOEL OESCRIPTION OF FETRA}

The modified FETRA code is an unsteady two-dimensional finite-element model, which uses the Galerkin weighted-residual method. The model consists of three submodels coupled to include the effects of sediment-contaminant interaction on contaminant transport. The submodels are: 1) a sediment transport submodel, 2) a dissolved-contaminant transport submodel, and 3) a particulate-contaminant (contaminant adsorbed by sediment) transport submodel.

The modified FETRA is applicable to coastal waters, rivers, and possibly well-mixed estuaries. However, since FETRA is a vertically integrated model, it cannot be applied to stratified estuaries, where vertical direction becomes very important. A three-dimensional model applicable to estuaries is described in Section 3 .

\subsubsection{Sediment Transport Submodel}

The sediment transport submodel calculates the migration of sediment (transport, deposition, and scouring) for three sediment-size fractions of cohesive and noncohesive sediments (e.g., sand, silt, and clay) separately, since movement and adsorption capacity vary significantly with sediment size. The model includes the mechanisms of: 
1. advection and dispersion of sediment,

2. wave motion to suspend sediments,

3. fali velocity and conesiveness,

4. deposition on the ocean and river beds,

5. erosion from the ocean and river oeds (bed erosion and armoring),

6. sediment contributions from outside point and nonpoint sources to the system and suosequent mixing.

Sediment mineralogy and water-quality effects are implicitly included through the above-mentioned mechanisms 3,4 , and 5 .

This submodel also calculates changes in ocean and river-bed conditions, including bed-elevation changes and distribution of sedinent-size fraction with in the bed.

The governing equation of sediment transport for the three-dimensional case is (Daily and Harleman 1966; Sayre 1766):

$$
\begin{aligned}
\frac{\partial C}{\partial t} j & +\frac{\partial}{\partial x}\left(U C_{j}\right)+\frac{\partial}{\partial y}\left(V C_{j}\right)+\frac{\partial}{\partial z}\left\{\left(W-\omega_{S j}\right) C_{j}\right\} \\
& =\frac{\partial}{\partial x}\left(\varepsilon_{x} \frac{\partial C}{\partial x} j\right)+\frac{\partial}{\partial y}\left(\varepsilon_{y} \frac{\partial C}{\partial y} j\right)+\frac{\partial}{\partial z}\left(\varepsilon_{z} \frac{\partial C}{\partial z} j\right)
\end{aligned}
$$

where

$$
\begin{aligned}
C_{j}= & \text { concentration of sediment of } j^{\text {th }} \text { size fraction (weight } \\
& \text { of sediment per unit volume of water) } \\
t= & \text { time } \\
U= & \text { velocity component of longitudinal }(x) \text { direction } \\
V= & \text { velocity component of lateral }(y) \text { direction } \\
W= & \text { velocity component of vertical }(z) \text { direction } \\
W_{S j}= & \text { fall velocity of sediment particle of } j^{\text {th }} \text { type }
\end{aligned}
$$



$x, y, z=$ longitudinal, lateral, and vertical directions in Cartesian coordinates, respectively $\begin{aligned} \varepsilon_{x}, \varepsilon_{y}, \varepsilon_{z}= & \text { diffusion coefficients of longitudinal, lateral, and } \\ & \text { vertical directions. }\end{aligned}$
Boundary conditions are:

$$
\begin{array}{lll}
\left(W-W_{S j}\right) C_{j}-\varepsilon_{z} \frac{\partial C}{\partial z} j=0 & \text { at } z=h \\
(1-\gamma) W_{S j} C_{j}+\varepsilon_{z} \frac{\partial C}{\partial z} j=S_{D J}-S_{R J} & \text { at } z=0 \\
C_{j}=C_{0 j} \quad \text { or } \quad V C_{j}-\varepsilon_{y} \frac{\partial C_{j}}{\partial y}=Q_{C j} & \text { at } y=0 \text { and } B
\end{array}
$$

where

$$
\begin{aligned}
B= & \text { width of a study area } \\
C_{0 j}= & \text { constant concentration of } j^{\text {th }} \text { sediment } \\
h= & \text { flow depth } \\
Q_{C j}= & \text { lateral influx of } j^{\text {th }} \text { sediment } \\
S_{D j}= & \text { sediment deposition rate per unit bed surface area for } \\
& j^{\text {th }} \text { sediment-size fraction } \\
S_{R j}= & \text { sediment erosion rate per unit bed surface area for } j \text { th } \\
& \text { sediment-size fraction } \\
r= & \text { re-entrainment coefficient, } i . e ., \text { probability that particle } \\
& \text { settling to the bed is re-entrained, }
\end{aligned}
$$

Since a value of $\gamma$ is not easily available for various flow conditions, $\gamma$ was assumed to be unity in this study; that is, for the same flow condition, all suspended matter settling on the river and ocean bed by the settling velocity re-entrains to the flow. In other words, there is no sediment-particle exchange between suspended and bottom sediments under an equilibrium condition of sediment transport. The vertical flow velocity, $W$, is also assumed to be negligible. 
Since velocity components and sediment concentration are generaliy not vertically uniform, the following methods, similar to a Fischer's approach (1357) was used nere:

$$
\begin{gathered}
c_{j}=\bar{C}_{j}+c_{j}^{\prime+} \\
U=\bar{U}+u^{\prime \prime} \\
V=\bar{V}+v^{\prime \prime} \\
\frac{\partial c_{j}^{\prime \prime}}{\partial x}=\frac{\partial c_{j}^{\prime \prime}}{\partial y}=\frac{\partial W_{s j}}{\partial z}=0
\end{gathered}
$$

where

$$
\begin{aligned}
\bar{c}_{j}, \bar{U}, \bar{V}= & \text { deptn averaged values of concentration of sediment for } \\
& j^{\text {tn }} \text { size fraction, longitudinal velocity, and lateral } \\
& \text { velocity, respectively } \\
c_{j}^{\prime \prime}, u^{\prime \prime}, v^{\prime \prime}= & \text { fluctuations from the depth averaged values of } \\
& \text { concentration of sediment of } j^{\text {th }} \text { size fraction, } \\
& \text { longitudinal velocity, and lateral velocity, respectively. }
\end{aligned}
$$

Note that $c_{j}$, $u^{\prime \prime}$, and $v^{\prime \prime}$ are spatial deviations, not temporal deviations as is usual in turbulance analysis; all of the temporal averaging has Deen carried out prior to writing Equation (1).

By substituting the above expressions into Equation (1) and integrating them over the entire flow depth, th is equation becomes: 


$$
\begin{aligned}
& \bar{C}_{j}\left\{\frac{\partial h}{\partial t}+\frac{\partial}{\partial x}(\bar{U} h)+\frac{\partial}{\partial y}(\bar{V} h)\right\}-\left.\left(\bar{C}_{j}+c_{j}^{\prime \prime}\right)\right|_{z=n}\left\{\frac{\partial h}{\partial t}+\left.\left(\bar{J}+u^{\prime \prime}\right)\right|_{z=n} \frac{\partial h}{\partial x}\right. \\
& \left.+\left(\bar{V}+v^{\prime \prime}\right) \mid n^{\frac{\partial n}{\partial y}}\right\}+\left\{w_{s_{j}}\left(\bar{C}_{j}+c_{j}^{\prime \prime}\right)\left|{ }_{z}+\varepsilon_{z} \frac{a\left(\bar{C}_{j}+c^{\prime \prime}{ }_{j}\right)}{\partial z}\right| z=n\right\} \\
& =-n\left(\frac{\partial \bar{C}}{\partial \bar{t}} j+\nabla \frac{\partial \bar{C}}{\partial y} j+\nabla \frac{\partial \bar{C}}{\partial y} j\right)+n \frac{\partial}{\partial x}\left(\varepsilon_{x} \frac{\partial \bar{C}}{\partial x} j\right)+n \frac{\partial}{\partial y}\left(\varepsilon_{y} \frac{\partial \bar{C}}{\partial y} j\right) \\
& -\frac{\partial}{\partial x} \int_{0}^{h} u^{\prime \prime} c_{j} " d z-\frac{\partial}{\partial y} \int_{0}^{n} v^{\prime \prime} c_{j} d z-\left\{w_{s}\left(\bar{C}_{j}+c_{j}{ }^{\prime \prime}\right) l=0\right. \\
& \left.+\varepsilon_{z} \frac{\partial \bar{i}_{j}+c_{j}^{\prime \prime}}{\partial z} \mid z_{z}=0\right\}
\end{aligned}
$$

The equation of continuity, the kinetic water-surface Doundary condition, and Equation (2) make the left side of Equation (9) zero. As in the Boussinesq diffusion-coefficient concept, let:

$$
\int_{0}^{h} u^{\prime \prime} c_{j}{ }^{\prime \prime} d z=\left(\overline{\left.u^{\prime \prime} c_{j}{ }^{\prime \prime}\right) h}=-n D_{x} \frac{\partial \bar{C}}{\partial x} j\right.
$$

and

$$
\int_{0}^{h} \quad v^{\prime \prime} c_{j}{ }^{\prime \prime} d z=\sqrt{\left.v^{\prime \prime} c_{j} "\right) h}=-h D_{y} \frac{\partial \bar{C}}{\partial y} j
$$

where $D_{x}$ and $D_{y}$ equal tne dispersion coefficients of $x$ and $y$ directions. Hence, Equations (2), (3), (9), (10), and (11) yield the following final expression of sediment transport: 


$$
\begin{aligned}
\frac{\partial \bar{C}}{\partial t} j & +\left(\bar{U}-\frac{D_{x}}{n} \frac{\partial h}{\partial x}\right) \frac{\partial x}{\partial x} j+\left(\bar{V}-\frac{D_{y}}{h} \frac{\partial h}{\partial y}\right) \frac{\partial \bar{C}_{j}}{\partial y} \\
& =\frac{\partial}{\partial x}\left(K_{x} \frac{\partial \bar{C}}{\partial x} j\right)+\frac{\partial}{\partial y}\left(K_{y} \frac{\partial \bar{C}_{j} j}{\partial y}\right)+\frac{S_{R j}}{\eta}-\frac{S_{D j}}{h}
\end{aligned}
$$

where

$$
\begin{aligned}
& k_{x}=\varepsilon_{x}+D_{x} \\
& K_{y}=\varepsilon_{y}+D_{y}
\end{aligned}
$$

The finite-elenent metnod was used to solve Equations (4) and (12). To solve Equations (4) and (12), sediment erosion and deposition rates, $S_{R j}$ and $S_{D j}$, must be evaluated for various water bodies.

Rivers

Sediment erosion and deposition rates are evaluated separately for each sediment-size fraction because erosion and deposition characteristics are significantly different for cohesive and noncohesive sediments.

Erosion and deposition of nonconesive sediments (sand and gravel) are affected by the amount of sediment tre flow is capable of carrying. For example, if the amount of sand being transported is less than the flow can carry for given hydrodynamic conditions, the current will scour sediment from the river bed to increase the sediment transport rate. This occurs until the actual sediment transport rate becomes equal to the carrying capacity of the flow, or until the available bed sediments are all scoured, whichever occurs first. Conversely, the flow deposits sand and gravel if its actual sediment transport rate is above the flow's capacity to carry sediment. Because of its simplicity, the following DuBoy's formula (Vanoni 1975), which was originaliy developed for rivers, was used to calculate the flow capacity of noncohesive sediment transport, $\mathrm{Q}_{\mathrm{T}}$ per unit width at a down-current point in rivers and possibly in well-mixed estuaries:

$$
Q_{T}=\Psi_{D} \tau_{b}\left(\tau_{b}-{ }^{T_{c}}\right)
$$


where

$$
\begin{aligned}
{ }_{b} & =\text { bed shear stress } \\
{ }_{c} & =\text { critical bed shear stress at which sediment movement begins. } \\
\Psi_{D} & =\text { coefficient. }
\end{aligned}
$$

Although the DuBoy's formula was developed as a bed-load formula, it has been widely used to calculate the total sediment load because of its simplicity (Vanoni 1975). Comparisons of computed and measured sediment loads for the Niobrara River near Cody, Neb. and the Colorado River at Taylor's Ferry, Colo., reveal that DuBoy's formula tends to overestimate a total sediment load under low flows, but provides better estimates under high flows (Vanoni 1975). The total sediment capacity per unit width, $Q_{T}$, was then compared with the actual amount of sand, $\mathrm{Q}_{\mathrm{T}}$ per unit width at an up-current point, being transported in the water. Hence:

$$
\begin{aligned}
& S_{R j}=\frac{Q_{T}-Q_{T a}}{\Delta L} \\
& S_{D j}=\frac{Q_{T a}-Q_{T}}{\Delta L}
\end{aligned}
$$

where

$\Delta L=$ distance between the up-current and down-current locations. For sediment erosion and deposition rates of cohesive sediments (silt and clay), the following Partheniades (1962) and Krone (1962) formulas were adopted:

$$
\begin{gathered}
S_{R j}=M_{j}\left(\frac{{ }^{\top} b}{{ }^{\tau_{C R}}}-1\right) \\
S_{D j}=W_{S j}{ }^{C} j\left(1-\frac{{ }^{\top} D}{{ }{ }_{C D}}\right)
\end{gathered}
$$


wnere

$$
\begin{aligned}
& M_{j}= \text { erodibility coefficient for sediment of } j^{\text {th }} \text { size fraction } \\
&{ }^{\top} C D_{j}= \text { critical shear stress for sediment deposition for } j{ }^{\text {th }} \\
& \text { sediment-size fraction } \\
&{ }^{\tau} C R_{j}= \text { critical shear stress for sediment erosion for } j \text { th } \text { sediment- } \\
& \text { size fraction. } \\
& V \\
& V \text { alues of } M_{j},{ }^{\tau} C D_{j} \text {, and }{ }^{\tau} C R_{j} \text { must de determined by field and/or }
\end{aligned}
$$
laboratory tests. These values selected for the Columbia River (Washington), the Clinch River (Tennessee), and Four Mile and Wolf Creeks (I owa) were reported in recent mathematical-simulation studies, concerning sediment, radionuclide, and pesticide transport in these four rivers, simulated by another sediment-contaminant transport model SERATRA (Onishi 1977; Onishi and Wise 1979). The actual amount of conesive sediment erosion is the amount calculated by Equation (14), or the total amount of available bed sediment for scouring, whichever is smaller.

When the fall velocity, $W_{s j}$, depends on sediment concentration, the fall velocity may be assumed (Krone 1962):

$$
w_{s}=K_{j} C_{j}^{4 / 3}
$$

where

$$
K_{j}=\text { an einpirical constant depending on the sediment type. }
$$

The applicability of Equations (13) through (17) to the James River estuary was shown in Onishi and wise (1978).

Oceans with Surface Waves

In most environments occurring in coastal areas, marine sediments are most $1 y$ suspended by waves, which themseives can transport only small amounts of suspended sediment. The sediment suspended by wave action is then transported mostly by a current that, in most cases, is too small to suspend sediment by itself. 
Similar to the computation of the erosion and deposition rates of noncohesive sediments in rivers and possibly well-mixed estuaries as discussed earlier, the following concept was used: If the amount of sand being transported is less than what the flow and wave can carry, the current and waves will scour sediment from the ocean bed to increase tne sediment transport rate. The scouring takes place until an actual sediment load is equal to the carrying capacity of the flow and waves, or until the available bed sedinents are all scoured, whichever occurs first. Conversely, the flow deposits sand if its actual sediment load is above the flow and wave capacity to carry sediment.

When surface waves are present, wave motion is assumed to be a dominant mechanism for suspension of sediment, which is then transported by a combination of an ambient velocity of incidental flow (those other than ones included by wave motion) and the second-order velocity components of waves. In th is case, the DuBoy's formula for calculating transport of noncohesive sediment in rivers was replaced by appropriate wave-sediment transport formulas for offshore and surf zones, as are presented below. Because of the lack of formulations to calculate rates of the cohesive sediment erosion and deposition by waves, Partheniades (1952) and Krone's (1962) formulas [Equations (16) and (17)] for conesive sediment were used for tne marine environment. Since these two formulas were originally developed for estuaries and have not been tested in coastal zones, selection of $M,{ }^{\top} C 0_{j}$ and ${ }^{\tau} C R_{j}$ in Equations (16) and (17) must be performed with great care through model calibration.

Offshore zone: Witn the wave energy spectrum as a starting point, results ootained by Einstein (1972) and Liang and wang (1973) were used to obtain the wave-induced sediment suspension in offshore zones. Both the wave-induced bed load and suspended sediment concentrations are calculated. For the bed load the following approacn was used: the probability that a sediment particle is set into motion is the same as the probability that the instantaneous lift on the particle is greater than its submerged weight. This probability, denoted by $p$, is given as follows (Liang and wang 1973):

$$
p=\frac{1}{\sqrt{2 \pi}} \int_{B^{\star} \psi-1 / 50}^{\infty} e^{-z^{2} / 2} d z
$$


where

$$
\begin{aligned}
& \Psi=\frac{\left(\rho_{S}-\rho\right)}{\rho \bar{u}^{2}} \mathrm{gD} \\
& B^{\star}=4 \\
& 1 / 50=1.5 \\
& \rho_{S}=\text { sediment density } \\
& \rho=\text { water density } \\
& r_{S}=\text { unit weight of sediment } \\
& g=\text { gravitational acceleration } \\
& D=\text { equivalent sediment-particle diameter } \\
& u=\text { average horizontal velocity in the boundary layer. } \\
& T h e \text { average bed concentration, } C_{0} \text {, is given by the following equation } \\
& \qquad \bar{C}_{0}=A_{0} p \gamma_{S}
\end{aligned}
$$

where $A_{0}$ is a constant whicn must be determined by experiment. Thus, with a known $A_{0}$ value, $C_{0}$ can be calculated if $u$ is known (see the expression for $\Psi$ ).

The velocity $u$ is obtained by treating the flow field in the turbulent boundary layer as a superposition of all the components in the random wave train. Thus, $u^{2}$ can be written as:

$$
\bar{u}^{2}=\sum_{i}\left(u_{0 i}^{2}\right)\left(1-2 f_{1 i} \cos f_{2 i}+f_{1 i}^{2}\right)
$$

where

$$
\begin{aligned}
& f_{1 i}=0.5 \exp \left(\frac{-133 \sinh \left(k_{i} h\right) z}{a_{i} \beta_{i}^{D}}\right) \\
& f_{2 i}=0.3\left(B_{i z}\right) \\
& 8_{i}=\frac{\omega_{i}}{2 v}
\end{aligned}
$$




$$
\begin{aligned}
a_{i} & =\text { wave amplitude } \\
w_{i} & =\text { wave frequency }(\mathrm{rad} / \mathrm{sec}) \\
h & =\text { water depth } \\
k_{i} & =\text { wave number } \\
z & =\text { vertical coordinate } \\
u_{0 i} & =a_{i} w_{i} / \sinh \left(k_{i} h\right) \\
\nu & =\text { kinematic viscosity of water. }
\end{aligned}
$$

The average bed load transport $Q_{B}$ is obtained by integrating as follows:

$$
Q_{B}=\bar{C}_{0} \quad \int_{0}^{2 D}\left(U_{B}+U_{A B}\right) d z
$$

where

$$
\begin{aligned}
U_{A B}= & \text { velocity component of incidental flow (tnose other than ones } \\
& \text { induced by a wave action) near the ocean bed } \\
U_{B}= & \text { mass transport velocity (second-order velocity components) of a } \\
& \text { wave near the ocean bed. }
\end{aligned}
$$

$U_{B}$ is calculated oy an expression obtained by Liang and wang (1973). The distribution of vertical velocity, $U_{A B}$, of the incidental flow is assumed to follow the 1/7-tn-power law (Scnlichting 1968). Hence, the bed load is transported by both wave-induced velocity and the incidental flow.

The concentration of the suspended sediment is calculated by taking the time average of the diffusion equation and solving a resulting linear elliptic equation obtained by neglecting the molecular diffusion coefficient and estimating the diffusion coefficients of wave motion and turbulence. The suspended sediment concentration at elevation $z$ with no deptin restriction is given by Liang and wang (1973).

$$
\frac{\mathrm{C}}{\overline{\mathrm{C}}_{0}}=\left[\frac{\tanh (k z / 2)}{\tanh \left(k z_{0} / 2\right)}\right]^{\mathrm{R}_{i}}, \quad z_{0}=2 \mathrm{D}
$$




$$
R_{i}=\frac{w_{s} \operatorname{sinn} k_{i}{ }^{\sigma} k_{i}{ }_{a_{i} \omega_{i}}}{r^{\sigma}}
$$

where

$$
\begin{aligned}
& \omega_{i}=\text { frequency } \\
& h=\text { water deptn } \\
& k_{i}=\text { wave number } \\
& r=3 /\left(2 o_{s} / \rho+1\right) \\
& a=\text { constant } \\
& a_{i}=\text { wave amplitude } \\
& w_{S}=\text { sediment-settling velocity } \\
& z=\text { vertical coordinate. }
\end{aligned}
$$

For the case of shallow water, the suspended sediment concentration $C$ at the elevation $z$ is given by Liang and wang (1973):

$$
\begin{aligned}
& \frac{C}{\bar{C}_{0}}=\left(\frac{2 D}{z}\right)^{\left|R_{i}\right|} \\
& R_{i}=\frac{W_{S}{ }^{h}}{r a a_{i} w_{i}}
\end{aligned}
$$

For this study, Equations (25) and (26) for a shallow-water case are used. The rate of suspended sediment transport in the interior zone $\left(Q_{S}\right)$ is then obtained as:

$$
Q_{S}=\int_{2 D}^{h} c\left(U_{S}+U_{I S}\right) d z
$$

where

$$
\begin{aligned}
\mathrm{U}_{\mathrm{IS}}= & \text { velocity component of incidental flow (those other than ones } \\
& \text { induced by wave action) in the interior zone }
\end{aligned}
$$




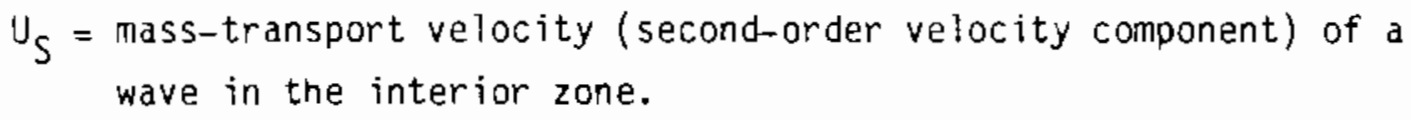

The mass-transport velocity, $U_{S}$, is calculated by Liang and Wang's expression (Liang and wang 1973). The vertical-velocity distribution of the incidental flow, $U_{I S}$, is assumed to follow the 1/7-th-power law. Hence, suspended sediment is also transported by both wave-induced velocity and the incidental flow.

Hence, the sediment transport capacity of flow for noncohesive sediment, $Q_{T}$, is:

$$
Q_{T}=Q_{B}+Q_{S}
$$

$\mathrm{Q}_{\mathrm{T}}$, thus obtained, can then be used to calculate the erosion and/or deposition rates of sand by Equations (14) and (15).

Surf zone: The forinulations discussed above are only applicable to regions well beyond the surf zone. The following expressions are used in the FETRA code to include the littoral (1ongshore) transport of sediments in the surf zone induced by the energy and momentum expended by breaking waves. The work of Komar (1977) and some of his associates was adopted for this study. The volumetric littoral transport rate $S_{\ell}$ and the immersed-weight littoral transport rate $I_{\ell}$ are given:

$$
\begin{aligned}
& S=\frac{I_{\ell}}{\left(\rho_{s}-\rho\right) g a^{\top}} \\
& I_{\ell}=0.28(E C n)_{D} \frac{\bar{v}_{\ell}}{u_{m}} \\
& u_{m}=\left[\frac{2 E_{b}}{\rho h_{b}}\right] 1 / 2
\end{aligned}
$$


where

$$
\begin{aligned}
(E C n)_{b}= & \text { the energy flux of the waves evaluated at the breaker zone } \\
E_{b}= & \text { the energy of the breaking waves } \\
n_{b}= & \text { the water depth at breaking } \\
v= & \text { velocity caused by the combination of waves and currents, } \\
& \left(\bar{v}_{\ell}=2.7 U_{m} \text { sin } a_{b} \cos x_{b}+U_{I}\right) \\
a_{b}= & \text { breaker angle with the shoreline } \\
U_{I}= & \text { velocity of incidental flow (those other than one induced by } \\
& \text { waves) in a surf zone } \\
a^{\prime}= & \text { an empirical constant }(\sim 0.6) .
\end{aligned}
$$

In the case where the mass transport is induced by wave action alone (in tne absence of otner currents, i.e., $\mathrm{U}_{\mathrm{I}}=0$ ), the longshore velocity becomes:

$$
\bar{v}_{\ell}=2.7 u_{m} \sin a_{b} \cos a_{b}
$$

Hence, the transport rates for this particular case are given by:

$$
\begin{gathered}
S_{\ell}=\left(6.85 \times 10^{-5}\right)\left(E C_{n}\right)_{b} \sin a_{b} \cos a_{b} \\
I_{\ell}=0.77\left(E C_{n}\right)_{b} \sin a_{b} \cos a_{b}
\end{gathered}
$$

The total sediment transport capacity, $Q_{T}$, is then calculated by:

$$
Q_{T}=a \cdot S_{2}
$$

where

$$
a=\text { unit conversion constant. }
$$

Rates of erosion and deposition of noncohesive sediment in a surf zone are then calculated by Equations (14) and (15). 
To use the above formulas for the offshore and littoral transport of sediment, temporal and spacial variations of wave characteristics, including the wave angle at breaking $a_{b}$, must be calculated. This was accomplished with 1) inclusion of wind-induced wave mechanisms in FETRA and 2) a wave refraction program, which is used in conjunction with FETRA.

For calculation of wave characteristics induced by wind, FETRA uses the following empirical formulations (U.S. Army Corps of Engineers 1962): waves generated by wind over fetches of known lengths can be computed by a method reported in Sverdrup and Munk (1947), Bretschneider (1953), and the Coastal Engineering Research Center's, Shore Protection Manual (U.S. Corps of Engineers, 1973).

$$
\begin{aligned}
& H_{S}=\frac{0.283 U_{w}^{2}}{g} \tanh \left[0.530\left(\frac{g d_{m}}{v_{w}^{2}}\right)^{0.75}\right] \tanh \left\{\frac{0.0125\left(\frac{g F_{\text {eff }}}{v_{w}^{2}}\right)^{0.42}}{\tanh \left[0.530\left(\frac{g d_{m}}{v_{w}^{2}}\right)^{0.75}\right]}\right\} \\
& T_{S}=\frac{1.2\left(2 \pi U_{w}\right)}{g} \tanh \left[0.833\left(\frac{g_{m}}{U_{w}^{2}}\right)^{0.375}\right] \tanh \left\{\frac{0.077\left(\frac{g F_{\text {eff }}}{u_{w}^{2}}\right)^{0.25}}{\tanh \left[0.833\left(\frac{g_{m}}{U_{w}^{2}}\right)^{0.375}\right]}\right\}
\end{aligned}
$$

where

$$
\begin{aligned}
H_{S} & =\text { significant wave height (feet) } \\
U & =\text { wind velocity (feet per second) } \\
g & =\text { acceleration due to gravity }\left(32.2 \mathrm{ft} / \mathrm{sec}^{2}\right. \text { ) } \\
d_{m} & =\text { mean fetch depth (feet) } \\
F_{e f f} & =\text { effective fetch length (feet) } \\
T_{S} & =\text { significant wave period (seconds) }
\end{aligned}
$$


The significant wave height, $\mathrm{H}_{S}$, is defined as the average of the one-third highest waves and can be related to the maximum wave height $\left(H_{\max }\right)$, nighest one percent $\left(\mathrm{H}_{1}\right)$ and nighest ten percent $\left(\mathrm{H}_{10}\right)$ waves, oy the following relationships (U.5. Corps of Engineers 1973).

$$
\begin{aligned}
H_{\text {max }} & =1.77 \mathrm{H}_{\mathrm{s}} \\
\mathrm{H}_{1} & =1.07 \mathrm{H}_{2} \\
\mathrm{H}_{10} & =1.27 \mathrm{H}_{\mathrm{s}}
\end{aligned}
$$

The wave amplitude, a, was calculated by:

$$
\begin{aligned}
H_{\text {RMS }} & =H_{S} / 1.416 \\
a & =H_{R M S} / 2
\end{aligned}
$$

The wave number was calculated by Equation (41) through an iteration process.

$$
\begin{gathered}
\omega=\frac{2 \pi}{T_{s}} \\
k=\omega^{2} /\left(g \cdot \tanh \left(k d_{m}\right)\right)=\frac{2 \pi}{L}
\end{gathered}
$$

where

$$
\begin{aligned}
& \omega=\text { wave frequency } \\
& K=\text { wave number } \\
& L=\text { wave length }
\end{aligned}
$$

The other method to obtain the necessary wave characteristics is to use the wave refraction program in conjunction with FETRA. This program was developed by Dobson (1967), and later modified by Ecker and Degraca (1974). The theoretical basis of the wave-refraction program is derived from geometrical optics, and uses the Snell's Law. The program uses wave hindcast data to obtain the representative deepwater waves for all wave directions and periods. From these deepwater waves, the program simulates the process by which each appropriate deepwater wave ray is generated toward shore. Starting from a known point on a contour grid with a given period and an initial direction, 
the computer program constructs a single wave ray step by step across the grid. At wave breaking, the program calculates the refraction coefficient, $K_{R}$; shoaling coefficient, $k_{s}$; the wave angle at breaking, $a_{b}$; the depth at breaking, $d_{b}$; and the wave heignt, $h_{D}$. The program also computes the longshore component of wave power at designated stations along the shoreline. The wave characteristics thus obtained oy the wave refraction program are then used by FETRA.

The following logic was used to compute bed conditions, including bed elevation changes, beds sediment size fraction and bed armoring. FETRA divides the river and ocean bed into a number of bed layers with a standard thickness, except for the top bed layer. The thickness of the top bed layer is equal to or less than the standard thickness at any given time. Each bed layer consists of a combination of clean or contaminated bed sediments of three size fractions (or types) selected for sediment transport as discussed above. Based on the sediment erosion or deposition rate, $S_{R j}$ or $S_{D j}$ calculated by Equations (14) through (17), sediment of each size fraction (or type) will be scoured from, or deposited to, the bed, changing the thickness of the top bed layer, and possibly a number of bed layers. When the top bed-layer thickness reaches more than the standard tnickness, due to net sediment deposition, a new top layer will be formed. On the other hand, when al\} the sediment in the top bed layer is scoured, the bed layer immediately below the original top layer becomes the new top layer. This process will continue until the actual sediment transport rate becomes equal to the carrying capacity of the flow or until the available bed sediment is all scoured, whichever occurs first.

One constraint to the bed erosion for the sediment of the second and the third size fractions (or types) is that the number of bed layers to be eroded for each of these two size fractions (or types) of sediments cannot exceed the number of bed layers eroded for the sediment of the first size fraction (or type). Bed sediment of the first sediment size fraction (or type) will cover and protect the sediments of the second and the third size fractions (or types) from erosion in bed layers not eroded for the first sediment size fraction (or type). 
Contaminant distributions associated with each sediment-size fraction (or type) within the ocean and river bed was obtained by keeping track of the amount of containinants removed from, or added to, each bed layer during a simulation period due to erosion or deposition of contaminated sediments and direct adsorption/desorption between dissolved contaminant and bed sedinents.

\subsubsection{Dissolved-Contaminant Transport Model}

The association of dissolved contaminants (sucn as radionuclides, heavy metals, pesticides, and nutrients) with sediments is assumed to be the prinary mechanism of contaminant uptake. Consequently, the model includes the mechanisms of:

1. advection and dispersion of dissolved contaminant

2. adsorption (uptake) of dissolved contaminant by sediments (conesive and noncohesive) or desorption from the sediments into water

3. radionuclide decay or other chemical and biological degradation of contaminant

4. contaminant contributions from point and nonpoint sources to the system (e.g., contaminant contributions from wastewater discharges, overland runoff flow, fallout and ground water to a surface water system) and subsequent mixing.

Effects of water quality (e.g., pH, water temperature, salinity) and sediment characteristics (e.g., clay minerals) are taken into account through changes in the distribution (or partition) coefficient, $k_{d j}$, and transfer rate, $K_{j}$, as shown in the last terin of Equation (42).

The governing equation of dissolved-contaminant transport for the threedimensional case is: 


$$
\begin{aligned}
\frac{\partial G_{W}}{\partial t} & +\frac{\partial}{\partial x}\left(U G_{W}\right)+\frac{\partial}{\partial y}\left(V G_{W}\right)+\frac{\partial}{\partial z}\left(W G_{W}\right) \\
& =\frac{\partial}{\partial x}\left(\varepsilon_{x} \frac{\partial G_{W}}{\partial x}\right)+\frac{\partial}{\partial y}\left(\varepsilon_{y} \frac{\partial G_{W}}{\partial y}\right)+\frac{\partial}{\partial z}\left(\varepsilon_{z} \frac{\partial G_{W}}{\partial z}\right) \\
& -\lambda G_{W}-\sum_{j} K_{j} C_{j}\left(K_{d j} G_{W}-G_{j}\right)
\end{aligned}
$$

In addition to the previously defined symbols:

$$
\begin{aligned}
k_{d j}= & \text { distrioution (or partition) coefficient between dissolved } \\
& \text { contaminant and particulate contaminant associated with } j^{\text {th }} \\
& \text { sediment } \\
K_{j}= & \text { transfer rate of contaminant for } j^{\text {th }} \text { sediment } \\
G_{j}= & \text { particulate-contaminant concentration associated with } j^{\text {th }} \\
& \text { sediment (weight of contaminant or radionuclide activity per unit } \\
& \text { weight of sediment) } \\
G_{w}= & \text { dissolved-contaminant concentration (weight of contaninant or } \\
& \text { radionuclide activity per unit volume of water) } \\
\lambda= & \text { radionuclide decay or, chemical and biological degradation rates of } \\
& \text { contaminant }
\end{aligned}
$$

Distribution coefficient, $k_{d j}$, is defined by:

$$
k_{d j}=\frac{f_{s j} / M_{j}}{f_{w} / V_{w}}=\frac{f_{s j}}{f_{w} C_{j}}
$$

where

$$
\begin{aligned}
& f_{S j}=\text { fraction of contaminant sorbed by } j^{\text {th }} \text { sediment } \\
& f_{W}=\text { fraction of contaminant left in solution } \\
& M_{j}=\text { weignt of } j^{\text {th }} \text { sediment } \\
& V_{w}=\text { volume of water } \\
& \frac{f_{S j}}{f_{w}}=\frac{C_{j} G}{G_{W}}
\end{aligned}
$$


Hence Equation (43) may be rewritten as:

$$
G_{j}=K_{d j} G_{w}
$$

The adsorption of contaminant by sediments, or desorption from the sedinents, is assumed to occur toward an equiliorium condition with the transfer rate, $k_{j}$, if the particulate-contaminant concentration differs from its equiliorium values as exprassed in Equation (44).

Literature review on the adsorption/desorption mechanisin reveals that a common way to express this mecnanism is to use a distribution coefficient, $k_{d j}$. A distribution coefficient is a function of many parameters, including radionuclide chemical state, water quality of a receiving water body, sediment sizes and clay minerals, and organic content. Unfortunately, the present knowledge on $k_{d j}$ is not advanced enough to deterinine these functional relationships. In this model, values of $k_{d j}$ will be assigned to the model as input data reflecting effects of these influencing variables. Actual $k_{d j}$ and $k_{j}$ values with $j$ th sediment may be obtained from field measurements or laboratory tests.

Tile boundary conditions for dissolved contaminant transport are:

$$
\begin{array}{ll}
W G_{W}-\varepsilon_{z} \frac{\partial G_{W}}{\partial z}=0 & \text { at } z=n \\
\varepsilon_{z} \frac{\partial G_{W}}{\partial z}=\sum_{j} r_{j}(1-P O R) D_{j} K_{D j}\left(K_{b j} G_{W}-G_{B j}\right) & \text { at } z=0 \\
V G_{W}-\varepsilon_{y} \frac{\partial G_{W}}{\partial y}=Q_{W} \quad \text { or } \quad G_{W}=G_{W O} & \text { at } y=0 \text { and } B
\end{array}
$$

where

$$
\begin{aligned}
D_{j}= & \text { diameter of } j^{\text {th }} \text { sediment } \\
G_{B j}= & \text { particulate-contaminant concentration per unit weight of sediment } \\
& \text { in } j^{\text {th }} \text { sediment size fraction in the ped }
\end{aligned}
$$




$$
\begin{aligned}
& G_{w_{0}}=\text { constant concentration of dissolved contarninant } \\
& K_{b j}=\text { transfer rate of contaminants witn } j^{\text {th }} \text { non-moving sedinent in } \\
& P O R=\text { porosity of bed sediment } \\
& Q_{W}=\text { lateral influx of dissolved contaminant } \\
& r_{j}=\text { specific weight of } j^{\text {th }} \text { sediment }
\end{aligned}
$$
contalninant detween dissolved contaminant and non-moving bed sediment. It was assuned that a contaminant nas the same distribution coefficient values, $k_{d j}$, for the moving (suspended and bed load sediments) and non moving (bed sediment without any motion) $j^{\text {th }}$ sediment. These two types of sediments, however, nave different transfer rates, $k_{j}$ and $k_{b j}$, as expressed in Equations (72) and (46). Direct adsorption by, and/or desorption from, bed sediment is assumed to occur only witn the sediment on the bed surface.

Let:

$$
\begin{aligned}
& G_{W}=\bar{G}_{W}+G_{W}^{\prime \prime} \\
& \frac{\partial G_{W}^{\prime \prime}}{\partial x}=\frac{\partial G_{W}^{\prime \prime}}{\partial y}=0
\end{aligned}
$$

where

$$
\begin{aligned}
\bar{G}_{W}= & \text { deptn-averaged value of pollutant concentration } \\
G_{W}= & \text { fluctuation from the depth-averaged value of pollutant } \\
& \text { concentration }
\end{aligned}
$$

By substituting the above expressions with tnose in Equations (5) tnrough (8), into Equation (42) and integrating it over the entire flow depth, Equation (42) becomes: 


$$
\begin{aligned}
& \bar{G}_{W}\left\{\frac{\partial h}{\partial t}+\frac{\partial}{\partial x}(\bar{J})+\frac{\partial}{\partial y}(\bar{V} h)\right\}-\left.\left(\bar{G}_{W}+G_{W}^{\prime \prime}\right)\right|_{z=n}\left\{\frac{\partial h}{\partial t}+\left.\left(\bar{U}+u^{\prime \prime}\right)\right|_{z=h} \frac{\partial h}{\partial x}\right. \\
& \left.+\left.\left(\bar{V}+v^{\prime}\right)\right|_{z=h} \frac{\partial h}{\partial y}\right\}+\left\{\left.\left(\bar{W}+W^{\prime \prime}\right)\left(\bar{G}_{W}+G_{W}^{\prime \prime}\right)\right|_{z=h}-\varepsilon_{z} \frac{\partial}{\partial z}\left(\bar{G}_{W}+G_{W}^{\prime \prime}\right)|| h\right\} \\
& =-h\left\{\frac{\partial \bar{G}_{W}}{\partial t}+\bar{U} \frac{\partial \bar{G}_{W}}{\partial x}+\bar{V} \frac{\partial \bar{G}_{w}}{\partial y}+D_{x} \frac{\partial h}{\partial x} \frac{\partial \bar{G}_{w}}{\partial x}+D_{y} \frac{\partial h}{\partial y} \frac{\partial \bar{G}_{w}}{\partial y}\right\} \\
& +n \frac{\partial}{\partial x}\left\{\left(\varepsilon_{x}+D_{x}\right) \frac{\partial \bar{G}_{w}}{\partial x}\right\}+n \frac{\partial}{\partial y}\left\{\left(\varepsilon_{y}+D_{y}\right) \frac{\partial \bar{G}_{W}}{\partial y}\right\} \\
& -\lambda h \bar{G}_{w}-h k_{j} \bar{C}_{j}\left(K_{d j} \bar{G}_{w}-G_{j}\right)-\left.\varepsilon_{z} \frac{\partial}{\partial z}\left(\bar{G}_{w}+G_{w}^{\prime \prime}\right)\right|_{z=0}
\end{aligned}
$$

The equation of continuity, the kinetic water-surface boundary condition and the boundary condition shown in Equation (45) then make the left side of Equation (50) zero. Hence, the final transport equation of dissolved contaminant is:

$$
\begin{aligned}
& \frac{\partial \bar{G}_{W}}{\partial t}+\left(\bar{U}-\frac{D_{x}}{h} \frac{\partial h}{\partial x}\right) \frac{\partial \bar{G}_{W}}{\partial x}+\left(\bar{V}-\frac{D_{y}}{h} \frac{\partial h}{\partial y}\right) \frac{\partial \bar{G}_{W}}{\partial y}=\frac{\partial}{\partial x}\left(k_{x} \frac{\partial \bar{G}_{W}}{\partial x}\right)+\frac{\partial}{\partial y}\left(K_{y} \frac{\partial \bar{G}_{W}}{\partial y}\right) \\
& -\left(\lambda+\sum_{j} K_{j} K_{d j} \bar{C}_{j}-\frac{1}{h} \sum_{j} Y_{j}(l-P O R) D_{j} K_{b j} K_{d j}\right) G_{W} \\
& +\sum_{j} K_{j} \bar{C}_{j} G_{j}-\frac{1}{n} \sum_{j} \gamma_{j}(1-P O R) D_{j} K_{b j} G_{B j}
\end{aligned}
$$

The boundary conditions for this equation are those in Equation (47).

\subsubsection{Particulate-Contaminant Transport Model}

The transport model of contaminants attached to sediments is solved separately for those adsorbed by each sediment size fraction of cohesive and noncohesive sediments. This model also includes the mechanisms of: 
1. advection and dispersion of particulate contaminant

2. adsorption (uptake) of dissolved contaminant by sediments or desorption from sediments into water

3. radionuclide decay, or chemical and biological degradation of contaminant

4. deposition of particulate contaminant on the ocean and river beds or erosion from the beds

5. contaminant contributions from point and nonpoint sources to the system (e.g., contaminant contributions from wastewater discharges, overland runoff flow, fallout, and ground water to a surface-water system) and sussequent mixing.

As in the transport of sediments and dissolved contaminant, the trireedimensional transport equation for contaminants adsorbed by the $j^{\text {th }}$ sediment size may be expressed as:

$$
\begin{aligned}
\frac{\partial C_{j} G_{j}}{\partial t} & +\frac{\partial}{\partial x}\left(U C_{j} G_{j}\right)+\frac{\partial}{\partial y}\left(V C_{j} G_{j}\right)+\frac{\partial}{\partial z}\left\{\left(W-W_{S_{j}}\right) C_{j} G_{j}\right\}=\frac{\partial}{\partial x}\left(\varepsilon_{x} \frac{\partial C_{j} G_{j}}{\partial x}\right) \\
& +\frac{\partial}{\partial y}\left(\varepsilon_{y} \frac{\partial C_{j} G_{j}}{\partial y}\right)+\frac{\partial}{\partial z}\left(\varepsilon_{z} \frac{\partial C_{j} G_{j}}{\partial z}\right)-\lambda C_{j} G_{j}-K_{j} C_{j}\left(G_{j}-K_{d j} G_{W}\right)
\end{aligned}
$$

where the particulate contaminant concentration, $G_{j}$, is assumed to be independent of $z$ as reported by Onishi, Schreiber and Codell (1980b). All symbols in Equation (52) were previously defined. Noting Equations (2), (3), and (4), the boundary conditions for this case Decome:

$$
\begin{array}{ll}
\left(W-W_{S j}\right) G_{j} G_{j}-\varepsilon_{z} \frac{\partial C_{j} G_{j}}{\partial z}=G_{j}\left\{\left(W-W_{S j}\right) C_{j}-\varepsilon_{z} \frac{\partial C_{j}}{\partial z}\right\}=0 & \text { at } z=n \\
(1-\gamma) W_{S j} C_{j} G_{j}+\varepsilon_{z} \frac{\partial C_{j} G_{j}}{\partial z}=G_{j} S_{D j}-G_{B j} S_{R j} & \text { at } z=0 \\
G_{j}=G_{j 0} \text { or } V C_{j} G_{j}-\varepsilon_{y} \frac{\partial C_{j} G_{j}}{\partial y}=Q_{j} & \text { at } y=0 \text { and } B
\end{array}
$$


where

$$
\begin{aligned}
& G_{B j}= \text { a particulate-contaminant concentration associated with } j^{\text {th }} \\
& \text { sediment in ocean or river bed. } \\
& G_{O j}= \text { constant concentration of particulate contaminant } \\
& Q_{j}= \text { lateral influx of particulate contaminant. } \\
&\text { Equation (56) is derived by } 1) \text { substituting Equations (5) through (8) into }
\end{aligned}
$$
Equation (52), 2) integrating it over the flow depth, 3) substrating equation Equation (9) multiplied by $G_{j}$ from the resulting equation, and 4) substituting the boundary conditions, Equations (53) and (54):

$$
\begin{aligned}
& \frac{\partial \hat{G}}{\partial t}+\left\{\bar{U}-\frac{2 \varepsilon_{x}}{\bar{C}_{j}} \frac{\partial \bar{C}_{j}}{\partial x}-\frac{D_{x}}{\bar{C}_{j}} \frac{\partial \bar{C}_{j}}{\partial x}+\frac{\varepsilon_{x}}{\bar{C}_{j} n} \frac{\partial n}{\partial x} c_{j z}^{\prime \prime} \mid=\frac{\partial \hat{G}_{j}}{\partial x}\right. \\
& +\left\{\bar{V}-\frac{2 \varepsilon_{y}}{\bar{c}_{j}} \frac{\partial \bar{C}_{j}}{\partial y}-\frac{D_{y}}{\bar{C}_{j}} \frac{\partial \bar{C}_{j}}{\partial y}+\left.\frac{\varepsilon_{y}}{\bar{C}_{j} h} \frac{\partial h}{\partial y} c_{j}^{\prime \prime}\right|_{z=n}\right\} \frac{\partial G_{j}}{\partial y} \\
& =\frac{\partial}{\partial x}\left(\varepsilon_{x} \frac{\partial G_{j}}{\partial x}\right)+\frac{\partial}{\partial y}\left(\varepsilon_{y} \frac{\partial G_{j}}{\partial y}\right)-\left(\frac{S_{R j}}{\bar{C}_{j} h}+\lambda+K_{j}\right) G_{j} \\
& +\left(K_{j} K_{d j} G_{W}+\frac{G_{B j} S_{R j}}{\bar{C}_{j}^{h}}\right)
\end{aligned}
$$

Since the two terins containing $c_{j}$ in the above equation are at least one order of magnitude smaller than the rest of the terms, these two terms may be omitted. Hence, the final expression becomes: 


$$
\begin{aligned}
\frac{\partial G}{\partial t} & +\left\{\bar{U}-\frac{2 \varepsilon_{x}}{\bar{C}_{j}} \frac{\partial \bar{C}_{j}}{\partial x}-\frac{D_{x}}{\bar{C}_{j}} \frac{\partial \bar{C}_{j}}{\partial x}\right\} \frac{\partial G_{j}}{\partial x}+\left\{\bar{V}-\frac{2 \varepsilon_{y}}{\bar{C}_{j}} \frac{\partial \bar{C}_{j}}{\partial y}-\frac{D_{y}}{\bar{C}_{j}} \frac{\partial \bar{C}_{j}}{\partial y}\right\} \frac{\partial G_{j}}{\partial y} \\
& =\frac{\partial}{\partial x}\left(\varepsilon_{x} \frac{\partial G_{j}}{\partial x}\right)+\frac{\partial}{\partial y}\left(\varepsilon_{y} \frac{\partial G_{j}}{\partial y}\right)-\left(\frac{S_{R j}}{\bar{C}_{j} n}+\lambda+K_{j}\right) G_{j} \\
& +\left(K_{j} K_{d} G_{W}+\frac{G_{B j} S^{S} j}{\bar{C}_{j} n}\right)
\end{aligned}
$$

The boundary conditions for this case are those expressed in Equation (55).

\subsubsection{Finite-Element Method}

Because of its increased solution accuracy and ready accomodation to various boundary geometrics (Desai and Abel 1972), the finite-element solution technique with the Galerkin weighted-residual method was used to solve Equations (12), (51), and (57) with the boundary conditions of Equations (4), (47), and (55). The flow domain is divided into a series of triangular elements interconnected at nodal points. Six nodes are associated with each triangle, three at the vertices and three on the mid-sides. A quadratic approximation is made for the sediment and contaminant concentrations within each element.

\subsection{EXAMINATION OF BASIC COMPUTATIONAL SCHEME}

The accuracy and convergence of the numerical solutions calculated by the modified FETRA were evaluated to examine the basic finite-element computational scheme of the model. Various simple equations were soived by FETRA and the computer results were then compared with known analytical solutions, including the following four cases.

\section{Case 1}

In the first example, the following one-dimensional, steady advectiondiffusion equation with a decay term was solved: 
$U \frac{d C}{d x}=\varepsilon_{x} \frac{d^{2} c}{d x^{2}}-a C$

With the boundary conditions of:

$$
\begin{array}{ll}
C=C_{0} & \text { at } x=0 \\
\frac{d C}{d x}=0 & \text { at } x=\ell
\end{array}
$$

Figure 1 shows computed results and analytical solution, assuming:

$$
U=5.0, \varepsilon_{x}=0.2, a=10.0, C_{0}=1.0 \text { and } \ell=1.0
$$

The figure indicates a very good agreement between computed and analytical solutions.

Case ?

In this second example, convergence of a time-dependent, one-dimensional solution to a steady-state solution was tested. The governing equation was:

$$
\frac{\partial C}{\partial t}=\varepsilon \frac{\partial^{2} C}{x x^{2}}-\alpha C
$$

with the following boundary condition:

$$
\begin{array}{llll}
C=0 & \text { in } 0 \leq x \leq l & \text { at } & t=0 \\
C=C_{0} & \text { at } x=0 & \text { at } & t>0 \\
\frac{\partial C}{\partial t}=0 & \text { at } x=\imath & \text { for all } & t
\end{array}
$$

Assuming $\varepsilon_{x}=0.2, \alpha=1.0, c_{0}=1.0$ and $\ell=1.0$, solutions are plotted in Figure 2, together with steady analytical and numerical solutions of the following equation: 


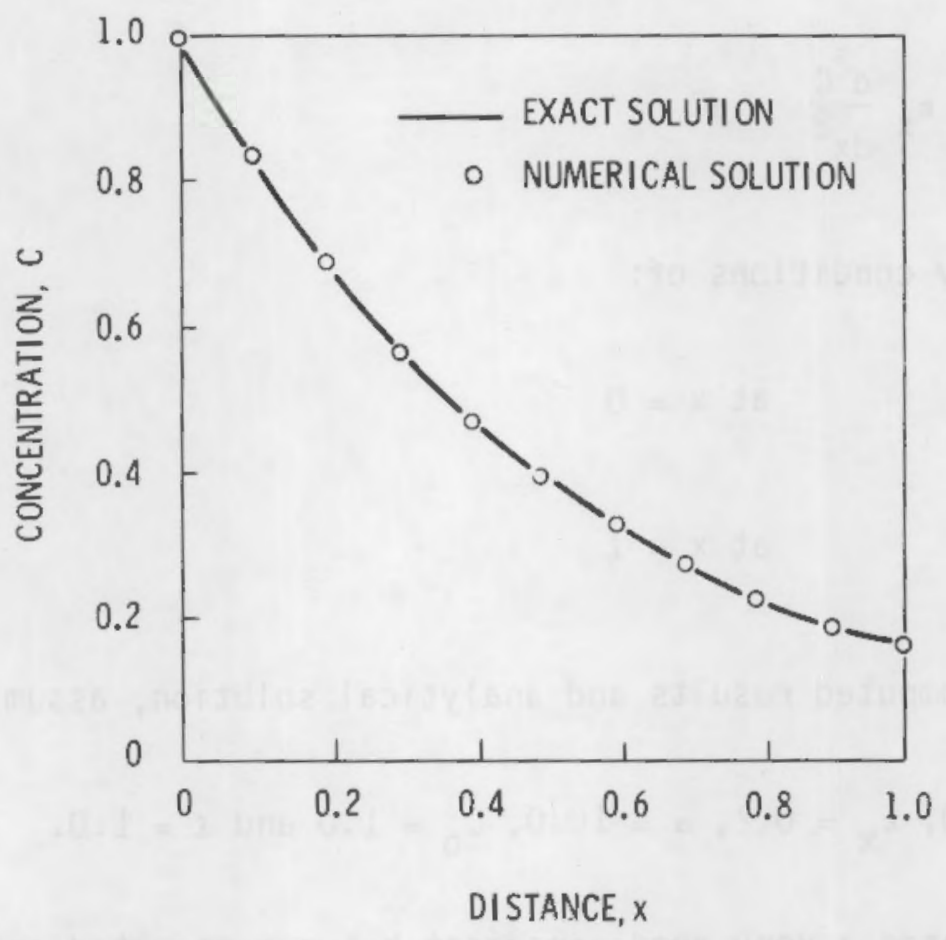

\section{FIGURE 1. Comparison of Numerical Solution with Analytical Solution of One-Dimensional Steady Advection- Diffusion Equation with a Decay Term}

$$
\varepsilon \frac{\partial^{2} c}{\partial x^{2}}-\alpha c=0
$$

As shown in Figure 2, unsteady numerical solutions converged to the steady-state exact solution. For runs with time $t$ greater than 4.0 , the numerical solutions coincide with the steady-state analytical solution. The steady-state numerical solution aiso agrees well with the exact solution.

\section{Case 3}

This case includes an unsteady, advection-diffusion equation:

$$
\frac{\partial C}{\partial t}+U \frac{\partial C}{\partial X}=\varepsilon \times \frac{\partial^{2} C}{\partial X^{2}}
$$




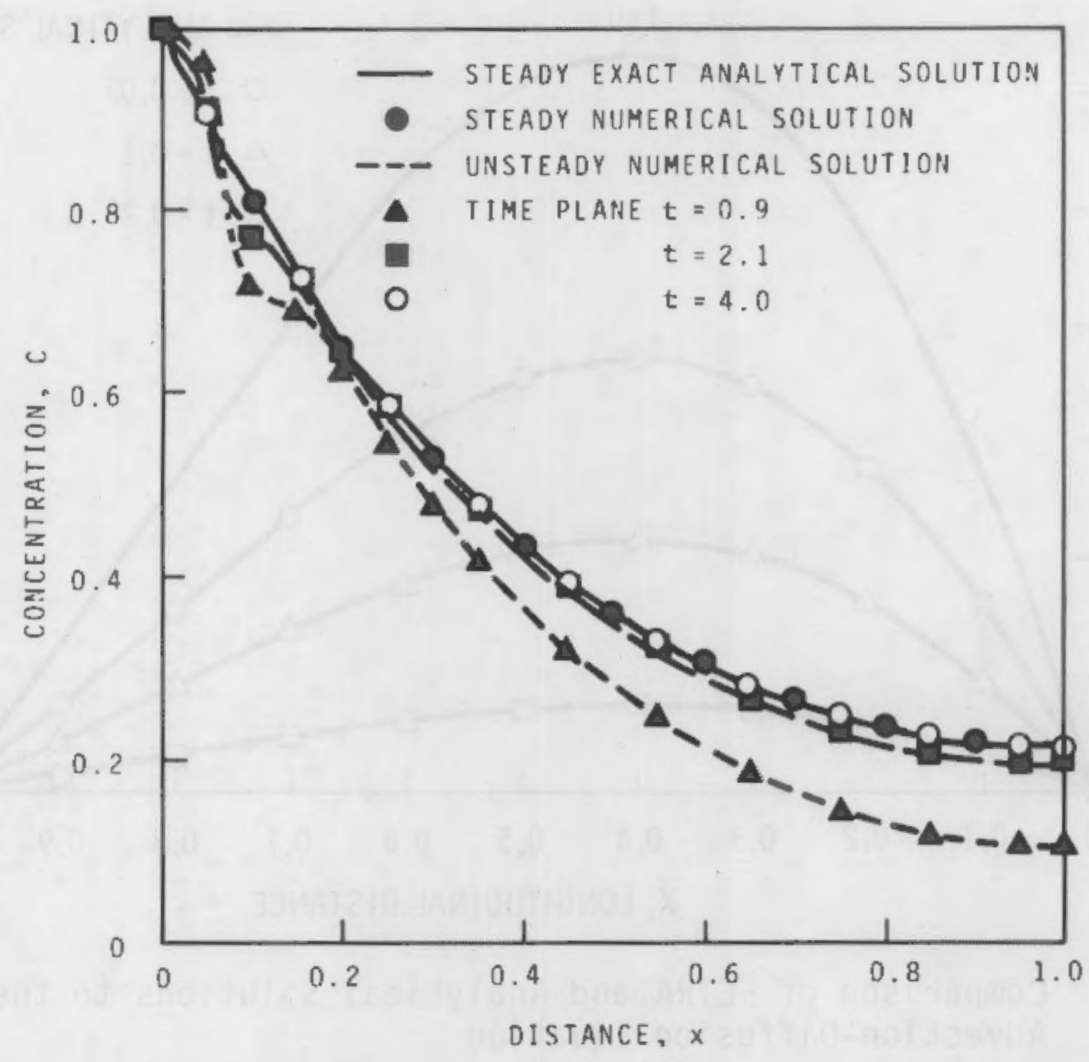

FIGURE 2. Convergence of Unsteady-State One-Dimensional Diffusion Equation to Steady-State Solution

Initial Condition:

$$
C(X, 0)=\operatorname{EXP}\left(\frac{-U X}{2 \varepsilon_{X}}\right) \operatorname{SIN}\left(\frac{\pi X}{\ell}\right)
$$

Boundary Conditions:

$$
\begin{aligned}
& C(0, t)=0 ., \quad C(\ell, t)=0 \\
& U=2 ., \varepsilon_{X}=1 . \quad \text { and } \ell=1 .
\end{aligned}
$$

As shown in Figure 3; comparison between computed results and analytical solution indicates good agreement. Stability criteria for FETRA were examined by using this example. The Courant Numbers, $C N$, and diffusion number, $D$, as defined below, were used for the stability criteria; 


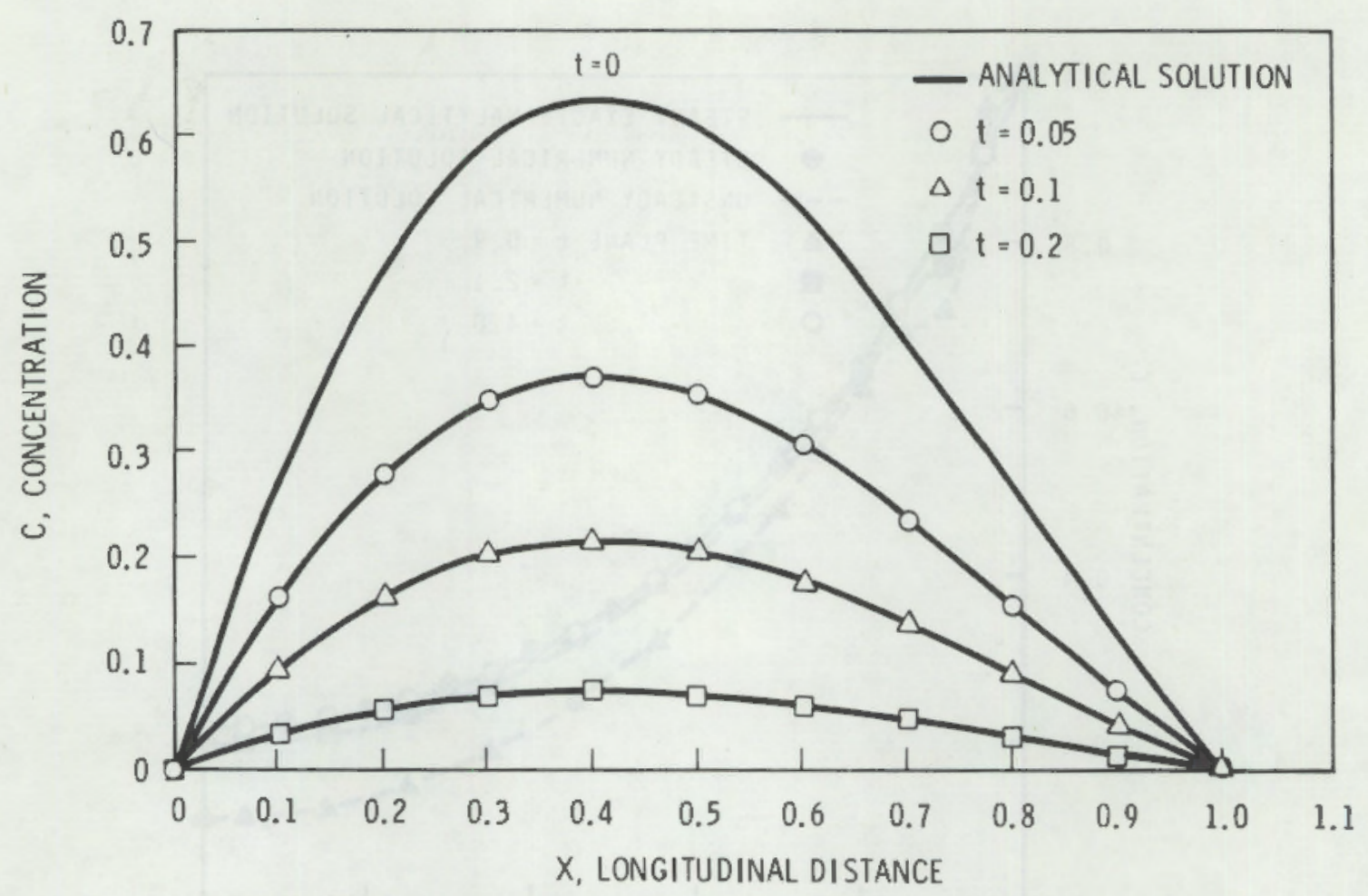

FIGURE 3. Comparison of FETRA and Analytical Solutions to the Unsteady Advection-Diffusion Equation

$$
\begin{aligned}
& C N=\frac{U \Delta t}{\Delta X} \\
& D=\frac{\varepsilon \times \Delta t}{\Delta X^{2}}
\end{aligned}
$$

Several computer runs were made to indicate the following results at time plane $t=0.2$ (see Figure 3 and Table 1 ). These results indicate that, under the conditions tested, combinations of Courant and Diffusion Numbers of 0.5 and 2.5 may be used if errors in solutions can be allowed several percent. However, if a long-term simulation is derived (that is, if a number of time steps are large), then $C N$ and $D$ values may have to be reduced to 0.1 and 0.5 , respectively.

\section{Case 4}

The following two-dimensional equation was solved numerically and computed results were compared with an analytical solution: 


$$
\begin{aligned}
& \text { TABLE 1. Stability Criteria }
\end{aligned}
$$

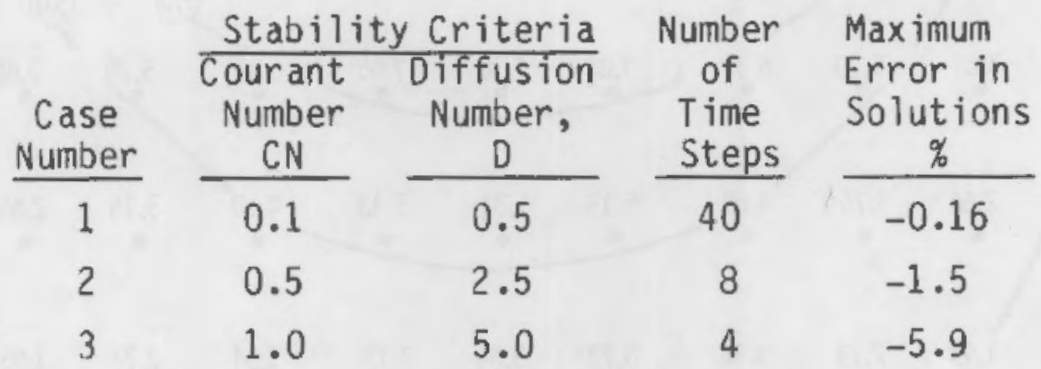

$$
\begin{aligned}
& \varepsilon \frac{\partial^{2} C}{x} \frac{x^{2}}{x^{2}} \frac{\partial^{2} C}{\partial y^{2}}=0
\end{aligned}
$$

with boundary conditions of:

$$
\begin{array}{lll}
C=0 & \text { at } & x=0 \\
C=0 & \text { at } & x=\ell \\
C=0 & \text { at } & y=0 \\
C=C_{0} \sin \left(\frac{\pi x}{\ell}\right) & \text { at } & y=\ell
\end{array}
$$

where $\varepsilon_{x}=\varepsilon_{y}=\ell=1.0$ and $C_{0}=10$. The analytical solution for this case is:

$$
C(x, y)=0.866 \sinh (\pi y) \sin (\pi x)
$$

The computer results and analytical solutions are shown in Figure 4 . Numbers in the figure are values of concentration $C$. Since the solutions are symetric with respect to $x=0.5$, computer results are given in the region of $0.5 \leq x \leq 1.0$, and analytical solutions are plotted in the region of $0 \leq x<$ 0.5. Comparison of these results reveals that there is an excellent agreement between the computed and analytical solutions.

As illustrated in Figures 1 through 4, the agreements of the model solutions and the exact solutions were excellent. 


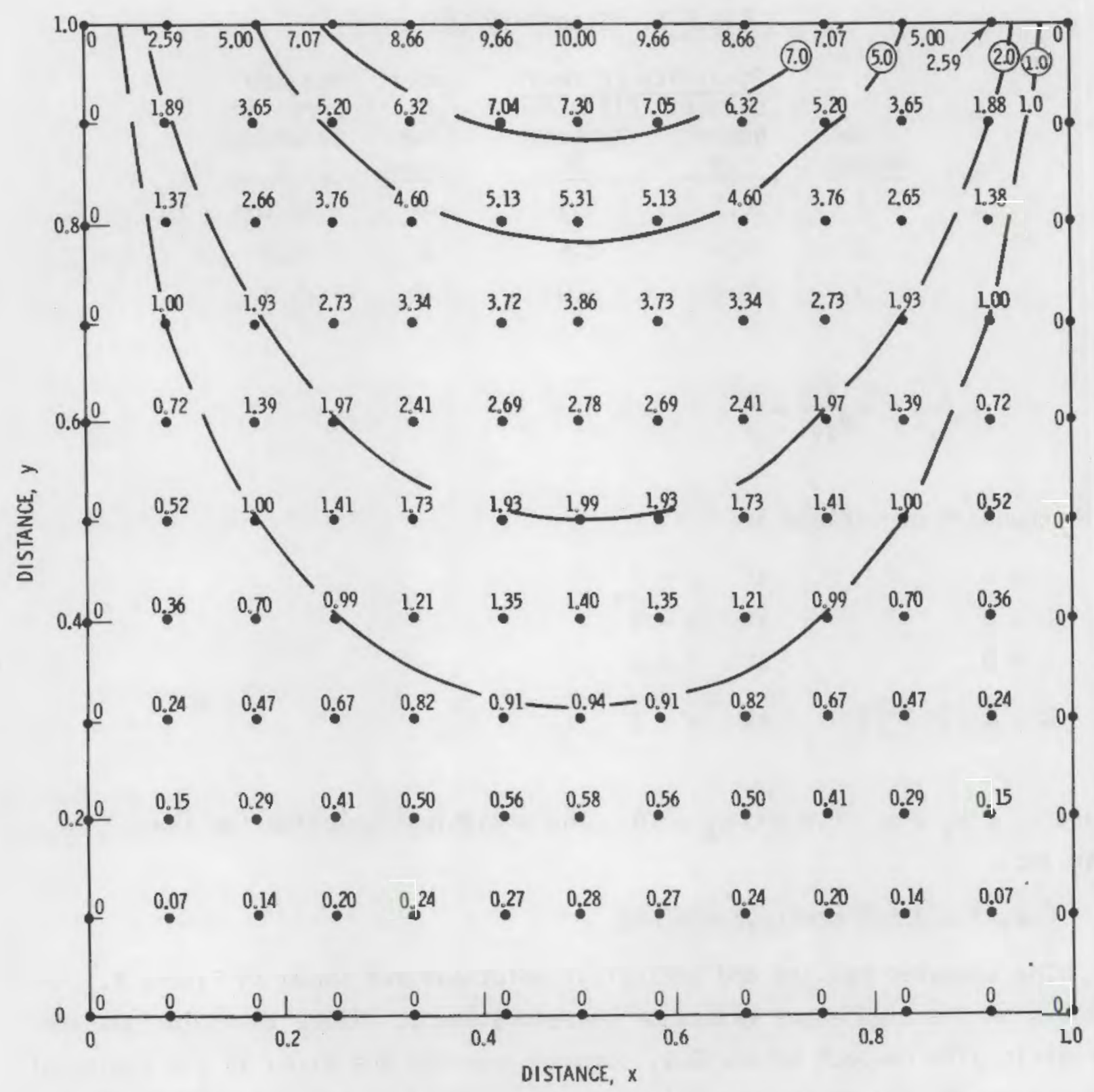

FIGURE 4. Comparison of Numerical Solution with Analytical Solution to Two-Dimensional Diffusion Equation

\subsection{SOME COMPUTATIONS OF SEDIMENT TRANSPORT CAPACITY UNDER MARINE ENVIRONMENT}

The primary modification made to FETRA was to include the wave-sediment interaction which occurs in marine and large lacustrine environments. In this section, sediment transport capacity, $Q_{T}$, in Equations (28) and (35) for 
offshore and surf zones were calculated. These values were then used to calculate noncohesive sediment erosion and deposition rate, $S_{R j}$ and $S_{D j}$, by Equations (14) and (15).

Simple examples of calculated noncohesive sediment load due to windinduced waves in an offshore zone are shown in Table 2 and Figure 5 . Table 2 indicates six different wind conditions (25 knots to 50 knots) tested to generate surface waves, which, in turn, suspend marine sediment. It was assumed that there are no external flow components except those caused by wave action alone. Computed suspended, bed, and total load (sum of suspended and bed loads) are shown in Figure 5. The computed sediment load (both suspended and bed-sediment loads) increases with wind velocity; and as expected, as wind velocity increases, increments of suspended load are greater than those of bed load. For example, at the wind speed of 25 knots, bed load consists of $80 \%$ of the total load, whereas the suspended load is only $20 \%$ of the total. However, at wind speed of 50 knots, bed load is only $25 \%$ of the total and suspended load consists of $75 \%$. There are no measured data to check the computed results.

The noncohesive-sediment transport capacity in a surf zone was also computed by FETRA. Assumed input data and predicted sediment load are presented in Table 3. The computed littoral transport rate was compared with the value reported in the U.S. Corps of Engineers Shore Protection Manual (1973), as shown in Figure 6. Solid lines in Figure 6 are those reported in the Shore Protection Manual. Comparison of these two cases indicates that FETRA

TABLE 2. Test Conditions of Sand Transport Capacities

\begin{tabular}{|c|c|c|c|}
\hline Case & $\begin{array}{l}\text { Wind } \\
\text { velocity, } \\
\text { knots } \\
\end{array}$ & $\begin{array}{c}\text { F low } \\
\text { Depth, } \\
\text { m }\end{array}$ & $\begin{array}{c}\text { Fetch } \\
\text { Length, } \\
\text { km }\end{array}$ \\
\hline 1 & 25 & 7.5 & 80 \\
\hline 2 & 30 & 7.5 & 80 \\
\hline 3 & 35 & 7.5 & 80 \\
\hline 4 & 40 & 7.5 & 80 \\
\hline 5 & 45 & 7.5 & 80 \\
\hline 6 & 50 & 7.5 & 80 \\
\hline
\end{tabular}




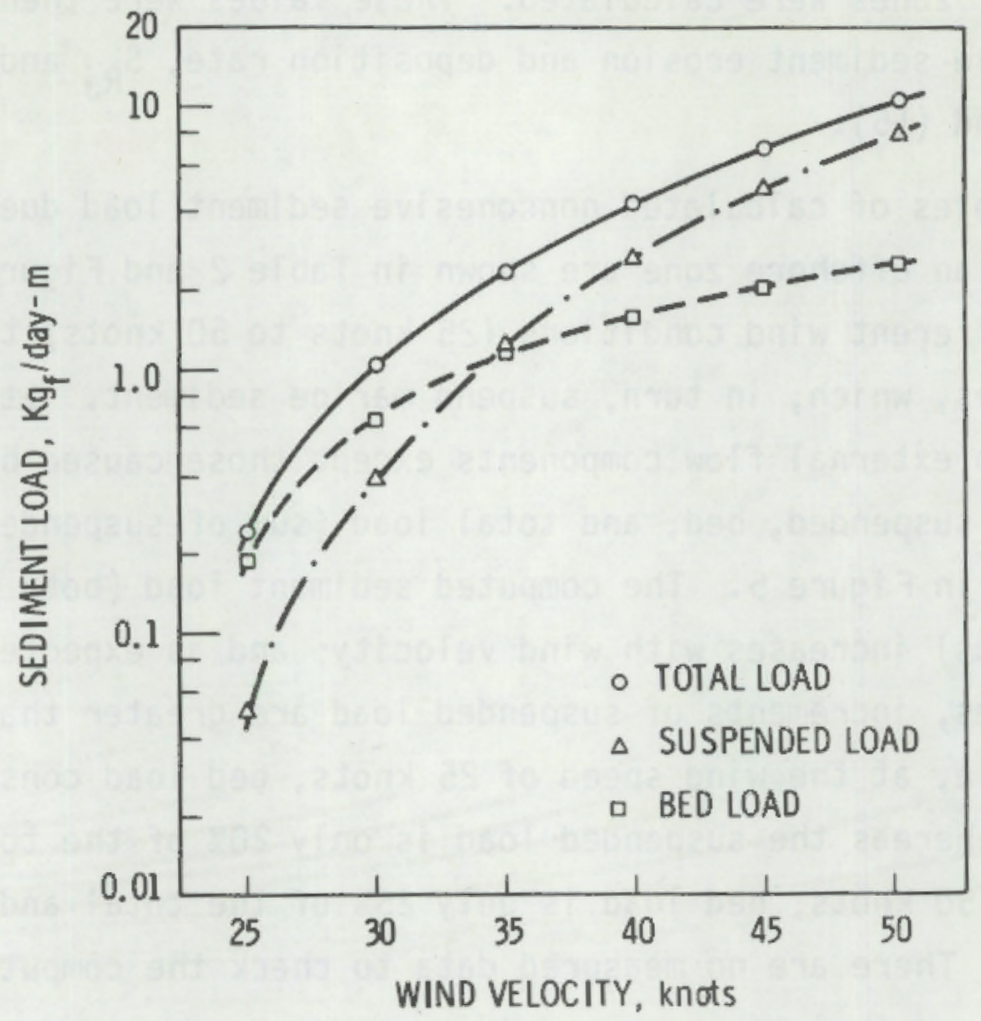

FIGURE 5. Calculated Sediment Load Due to Wind-Induced Waves in Marine Environment

TABLE 3. Input Parameters and Computed Sediment Transport Capacity in a Surf Zone

\begin{tabular}{|c|c|c|}
\hline Input & $\therefore$ Data & Computer Sediment Load \\
\hline Depth & $1.561 \mathrm{~m}$ & $\begin{array}{l}\text { Surf Zone Littoral } 3.39 \times 10^{7} \mathrm{kgf} / \text { day } \\
\text { Transport }\end{array}$ \\
\hline $\begin{array}{l}\text { Wave Heignt } \\
\text { at Breaking }\end{array}$ & $1.219 \mathrm{~m}$ & \\
\hline Wave Number & $0.321 \mathrm{~m}^{-1}$ & \\
\hline Sediment Density & $\begin{array}{l}188.5 \mathrm{kgf}^{2} \\
\mathrm{sec}^{2} / \mathrm{m}^{4}\end{array}$ & \\
\hline Water Density & $\begin{array}{l}102.0 \mathrm{kgf}^{-} \\
\mathrm{sec} 2 / \mathrm{m}^{4}\end{array}$ & \\
\hline $\begin{array}{l}\text { Breaker Angle } \\
\text { with Shoreline }\end{array}$ & $45^{\circ}$ & \\
\hline
\end{tabular}




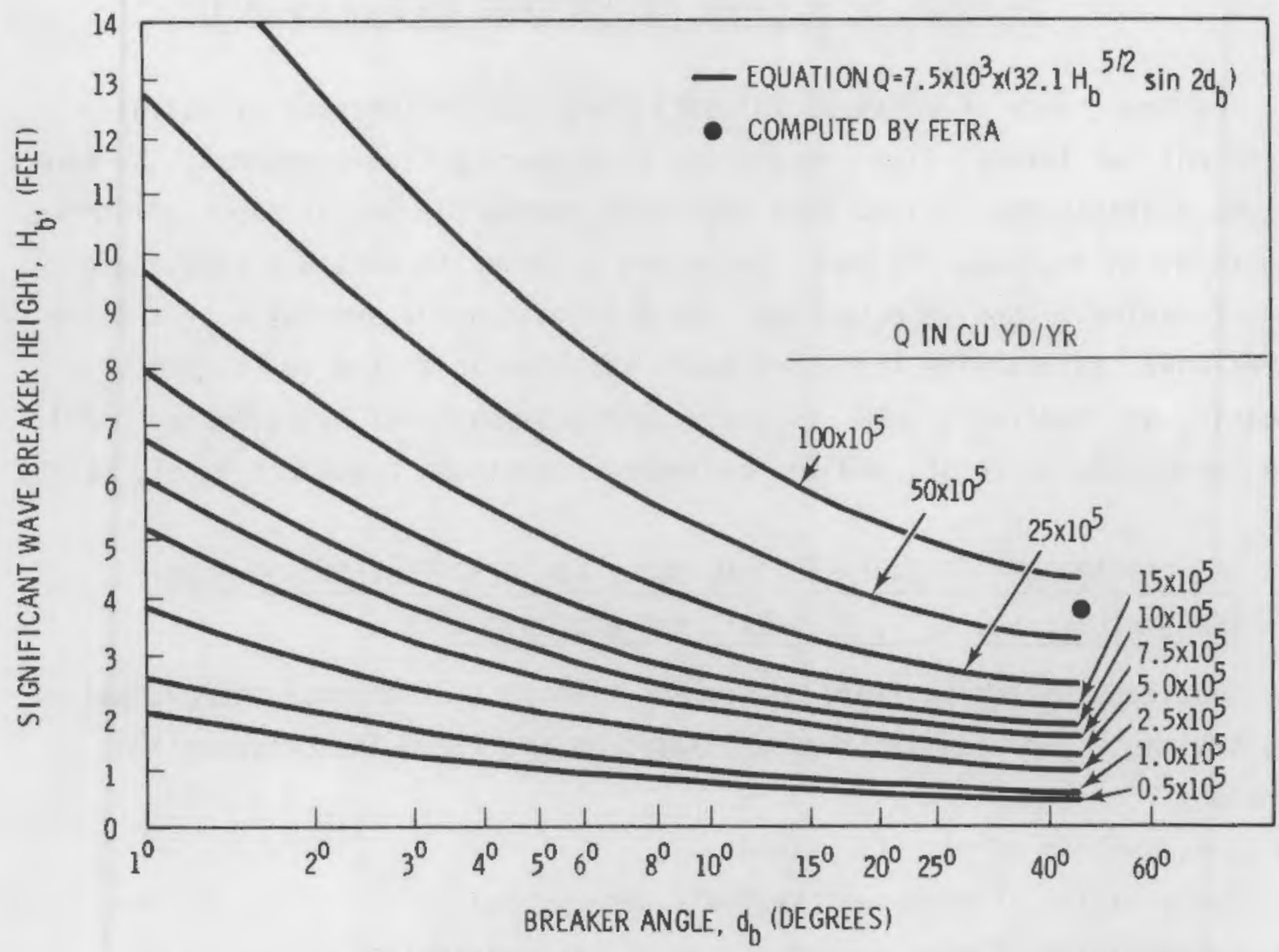

FIGURE 6. Longshore Transport Rate as a Function of Breaker Height and Breaker Angle, Together with Sediment Load Computed by the FETRA Code

predicted littoral transport rate to be $3.39 \times 10^{7} \mathrm{~kg}_{\mathrm{f}} /$ day, while the Shore Protection Manual indicates $4.05 \times 10^{7} \mathrm{~kg}_{\mathrm{f}} /$ day. Hence, FETRA's value is approximately $20 \%$ smaller. The Shore Protection Manual reports that the empirical formula used in the Manual tends to overestimate the sediment transport capacity at higher values of wave-breaking height and breaker angle. The same report also states that the formula used in the Shore protection Manual estimates approximately twice the equivalent value from the design curve (Figure 2-22) of the U.S. Army Coastal Engineering Research Center (CERC) technical Report No. 4 (1966). Thus, the predicted noncohesive sediment transport capacity in a surf zone computed by FETRA is reasonable. 


\subsection{TRANSPORT OF SEOIMENT AND RADIONUCLIOES IN ESTUARIES}

The importance of vertical velocity distribution (because of salinity intrusion) and lateral flow circulation to estuarine flow phenomena, and consequent sediment and radionuclide migration, makes the inclusion of all three dimensions in an estuarine model necessary in order to obtain accurate migration of radionuclides in estuaries. To fill this need, synthes is of a threedimensional radionuclide transport model was also initiated in FY -1979 by combining and modifying a PNL unsteady, three-dimensional hydrothermal model, developed by $\mathrm{D}$. S. Trent, and the sediment-contaminant transport model, FETRA.

\subsection{DESCRIPTION OF THREE-DIMENSIONAL MODEL FOR DISTRIBUTIONS OF FLOW,} TEMPERATURE, SALINITY, SEDIMENT, ANO RADIONUCLIOES

Equations governing fluid motion and transport of thermal energy, salinity, sediment, and radionuclides are based on the following conservation principles:

- conservation of mass for fluid

- conservation of momentum (Newton's Second Law)

- conservation of energy (Second Law of Thermodynamics)

- conservation of mass for salinity

- conservation of mass for sediment

- conservation of mass for radionuclides.

In addition, the Equation of State in the following form is required for the definition of a temperature-salinity dependent fluid property.

$$
\circ=F(P, T, S)
$$

where

$$
\begin{aligned}
& F=\text { functional relationship } \\
& P=\text { pressure } \\
& S=\text { salinity concentration } \\
& T=\text { water temperature } \\
& \rho=\text { fluid density }
\end{aligned}
$$


The following assumptions and/or restrictions were made:

- fluid is incompressible,

- only gravitational and Coriolis forces are included as body forces,

- free surface effects are considered,

- fluid is Newtonian,

- equations for turbulent flow are time averaged and Reynolds stresses are incorporated through appropriate eddy viscosity models,

- the Boussinesq approximation holds (i.e., $|\Delta \rho / \rho| \ll 1$ ).

The governing equations in the Cartesian Coordinate $(R, X, Z)$ in which $Z$ is perpendicular to the geopotential surface (vertical and positive upward) are shown below:

\section{Equation of Continuity for Flow}

$$
\frac{\partial U}{\partial R}+\frac{\partial W}{\partial X}+\frac{\partial V}{\partial Z}=0
$$

Symbols $U, W$, and $V$ refer to velocity components in the $R, X, Z$ directions, respectively.

Momentum Equations for Flow:

$R$ - direction component, $U$ :

$$
\begin{aligned}
& \frac{\partial U}{\partial t}+\frac{\partial}{\partial R}(U U)+\frac{\partial}{\partial X}(W U)+\frac{\partial}{\partial Z}(V U)=-\frac{1}{\rho_{0}} \frac{\partial P}{\partial R}+F_{c} W \\
& +\frac{\partial}{\partial R}\left(\varepsilon \frac{\partial U}{\partial R}\right)+\frac{\partial}{\partial X}\left(\varepsilon \frac{\partial U}{\partial X}\right)+\frac{\partial}{\partial Z}\left(\varepsilon \frac{\partial U}{\partial Z}\right)+S_{R}
\end{aligned}
$$

where

$$
S_{R}=\frac{\partial \varepsilon}{\partial R} \cdot \frac{\partial U}{\partial R}+\frac{\partial \varepsilon}{\partial X} \frac{\partial W}{\partial R}+\frac{\partial \varepsilon}{\partial Z} \cdot \frac{\partial V}{\partial R}-F_{R}^{b}-F_{R}^{S}
$$


and

$$
\begin{aligned}
F_{C} & =\text { Cariolis parameter } \\
F_{R}^{b} & =\text { bottom shear stress } \\
F_{R}^{S} & =\text { wind shear stress } \\
P & =\text { pressure } \\
t & =\text { time } \\
E & =\nu+v_{T} \\
\nu & =k \text { inematic viscosity } \\
v_{T} & =\text { turbulent diffusion coefficient for momentum } \\
{ }_{0} & =\text { reference flow density }
\end{aligned}
$$

The following expressions were used for bottom and wind-shear stresses:

$$
\begin{array}{ll}
F_{R}^{b}=K_{R} U^{N} & \text { for form drag } \\
F_{R}^{D}=(f / D) U^{N} & \text { for friction drag } \\
F_{R}^{S}=C_{a} \circ_{a} W_{a}^{2} \sin \Psi &
\end{array}
$$

where

$$
\begin{aligned}
C_{a} & =\text { resistance coefficient } \\
D & =\text { characteristic length } \\
f & =\text { Darcy friction factor } \\
K_{R} & =\text { form drag coefficient } \\
W_{a} & =\text { wind speed at } 10 \text {-meter level } \\
\rho_{a} & =\text { atomospheric density } \\
\Psi & =\text { angle between the wind direction and the } X \text {-axis }
\end{aligned}
$$

the Coriolis force is expressed as

$$
F_{c}=2 \omega \sin \phi
$$


where

$$
\begin{aligned}
& \phi=\text { latitude } \\
& \omega=\text { earth's angular velocity } \\
& X \text { - direction component, W: } \\
& \quad \frac{\partial W}{\partial t}+\frac{\partial}{\partial R}(U W)+\frac{\partial}{\partial X}(W W) \frac{\partial}{\partial Z}(V W)=-\frac{1}{\rho_{0}} \frac{\partial P}{\partial X}-F_{C} U \\
& \quad+\frac{\partial}{\partial R}\left(\varepsilon \frac{\partial W}{\partial R}\right)+\frac{\partial}{\partial X}\left(\varepsilon \frac{\partial W}{\partial X}\right)+\frac{\partial}{\partial Z}\left(\varepsilon \frac{\partial W}{\partial Z}\right)+S_{X}
\end{aligned}
$$

where

$$
\begin{aligned}
& S_{X}=\frac{\partial \varepsilon}{\partial R} \frac{\partial U}{\partial X}+\frac{\partial \varepsilon}{\partial X} \frac{\partial W}{\partial X}+\frac{\partial \varepsilon}{\partial Z} \frac{\partial V}{\partial Z}-F_{X}^{b}-F_{X}^{S} \\
& F_{X}^{b}=K_{R} W^{N} \\
& F_{X}^{b}=(f / 0) W^{N} \\
& F_{x}^{S}=C_{a^{p} a W_{a}^{2}} \cos \psi \\
& Z \text { - direction component, } V \\
& \text { for form drag } \\
& \text { for friction drag } \\
& \frac{\partial V}{\partial t}+\frac{\partial}{\partial R}(W V)+\frac{\partial}{\partial X}(W V)+\frac{\partial}{\partial Z}(V V)=-\frac{1}{\rho_{0}} \frac{\partial P}{\partial Z}+\frac{\rho}{\rho_{0}} g_{Z} \\
& +\frac{\partial}{\partial R}\left(\varepsilon \frac{\partial V}{\partial R}\right)+\frac{\partial}{\partial X}\left(\varepsilon \frac{\partial V}{\partial X}\right)+\frac{\partial}{\partial Z}\left(\varepsilon \frac{\partial V}{\partial Z}\right)+S_{Z}
\end{aligned}
$$

where

$$
\begin{array}{ll}
\quad S_{Z}=\frac{\partial \varepsilon}{\partial R} \cdot \frac{\partial U}{\partial Z}+\frac{\partial \varepsilon}{\partial X} \cdot \frac{\partial W}{\partial Z}+\frac{\partial \varepsilon}{\partial Z} \cdot \frac{\partial V}{\partial Z}-F_{Z}^{b}-F_{Z}^{S} \\
F_{Z}^{b}=K_{R} V^{N} & \text { for form drag } \\
F_{Z}^{b}=(f / D) V^{N} & \text { for friction drag }
\end{array}
$$


$g_{2}=$ gravitational force

\section{Energy:}

The governing equation for heat transfer is shown by

$$
\begin{aligned}
& \rho_{0} C_{p}\left[\frac{\partial T}{\partial t}+\frac{\partial}{\partial R}(U T)+\frac{\partial}{\partial X}(W T)+\frac{\partial}{\partial Z}(V T)\right] \\
& =\frac{\partial}{\partial R}\left(J \frac{\partial T}{\partial R}\right)+\frac{\partial}{\partial X}\left(\sigma \frac{\partial T}{\partial X}\right)+\frac{\partial}{\partial Z}\left(\sigma \frac{\partial T}{\partial Z}\right)
\end{aligned}
$$

where

$$
\begin{aligned}
& C_{p}=\text { specific heat } \\
& \sigma=k+{ }^{k} T \\
& k=\text { thermal conductivity } \\
& { }^{K_{T}}=\text { turbulent (eddy) thermal conductivity } \\
& \text { Salinity }
\end{aligned}
$$

The three-dimensional distribution of salinity is expressed by

$$
\frac{\partial S}{\partial t}+\frac{\partial}{\partial R}(U S)+\frac{\partial}{\partial X}(W S)+\frac{\partial}{\partial Z}(V S)=\frac{\partial}{\partial R}\left(D_{R} \frac{\partial S}{\partial R}\right)+\frac{\partial}{\partial X}\left(D_{X} \frac{\partial S}{\partial X}\right)+\frac{\partial}{\partial Z}\left(D_{Z} \frac{\partial S}{\partial Z}\right)
$$

where

$$
\begin{aligned}
D_{R}, D_{X}, D_{Z} & =\text { dispersion coefficient for } R, X, Z \text { directions } \\
S & =\text { salinity concentration }
\end{aligned}
$$

\section{Sediment Transport}

The migration (transport, deposition, and scouring) of sediment is solved for each size fraction (or sediment type) of cohesive and noncohesive sediment separately, since the movements and adsorption capacities of sediment vary significantly with sediment size, or sediment types. Three-dimensional transport of $j^{\text {th }}$ sediment is expressed by Equations (1) through (4). In this 
model, however, the net sediment flux across the vertical and lateral boundaries shown in Equations (3) and (4) are expressed as sink/source terms in the governing equation, as shown below. (Note that symbols of coordinate axes and corresponding velocities for Equations (1) and (65) are different.)

$$
\begin{aligned}
\frac{\partial C_{j}}{\partial t}+ & \frac{\partial}{\partial R}\left(U C_{j}\right)+\frac{\partial}{\partial X}\left(W C_{j}\right)+\frac{\partial}{\partial Z}\left\{\left(V-V_{s j}\right) C_{j}\right\} \\
& =\frac{\partial}{\partial R}\left(\varepsilon_{R} \frac{\partial C_{j}}{\partial R}\right)+\frac{\partial}{\partial X}\left(\varepsilon_{X} \frac{\partial C_{j}}{\partial X}\right)+\frac{\partial}{\partial Z}\left(\varepsilon_{Z} \frac{\partial C_{j}}{\partial Z}\right) \\
& +\left(\frac{S_{R j}}{\Delta Z}-\frac{S_{D j}}{\Delta Z}\right)+\frac{Q C_{j}}{\Delta X}
\end{aligned}
$$

The boundary conditions are

$$
\begin{array}{rlrl}
\left(V-V_{s j}\right) C_{j}-\varepsilon_{Z} \frac{\partial C_{j}}{\partial Z} & =0 & \text { at } Z=h \\
(1-\gamma) V_{s j} C_{j}+\varepsilon_{Z} \frac{\partial C_{j}}{\partial Z} & =0 & \text { at } Z=0 \\
\frac{\partial C_{j}}{\partial X}=0 & \text { at } X=0 \\
\frac{\partial C_{j}}{\partial X}=0 & \text { at } X=B
\end{array}
$$

where

$B=$ estuarine width

$C_{j}=$ sediment concentration of $j^{\text {th }}$ sediment

$h=$ flow depth

$Q_{c j}=$ lateral influx of $j^{\text {th }}$ sediment

$\lambda=$ re-entrainment coefficient

$\varepsilon_{R}, \varepsilon_{X}$ and $\varepsilon_{Z}=$ diffusion coefficients in $R, X$ and $Z$ directions

$S_{D j}=j^{\text {th }}$ sediment deposition rate per unit surface area 


$$
\begin{aligned}
& S_{R j}=j^{\text {th }} \text { sediment erosion rate per unit surface area } \\
& V_{S j}=\text { fall velocity of } j^{\text {th }} \text { sediment }
\end{aligned}
$$

Similar to the model FETRA, erosion and deposition rates of $j^{\text {th }}$ sediment, $S_{R j}$ and $S_{D j}$, are calculated by Equations (14) and (15) for nonconesive sediment, and Equations (16) and (17) for cohesive sediment.

Equation (65) with associated boundary conditions include mechanisms of:

1. advection and dispersion of sediment

2. fall velocity and cohesiveness

3. deposition on the river bed

4. erosion from the river bed (bed erosion and armoring)

5. sediment contributions from outside point and nonpoint sources to the system and subsequent mixing.

Sediment mineralogy and water-quality effects are implicitly included through the above-mentioned mecnanisms 3,4 , and 5 .

The sediment transport submodel also calculates changes in river-bed conditions, including bed-elevation changes and distribution of sediment size fraction witnin the bed.

Dissolved-Contaminant Transport

Transport and fate of dissolved contaminant (e.g., radionuclides) in three-dimensions can be expressed by Equations (42), (45), (46), and (47). These equations include mechanisins of:

1. advection and dispersion of dissolved contaminant

2. adsorption (uptake) of dissolved contaminant by sediments (conesive and noncohesive sediments) or desorption from the sediments into water

3. radionuclide decay or other chemical and biological degradation of contaminant 
4. contaminant contributions from point and nonpoint sources to the system (e.g., contaminant contributions from wastewater discharges, overland runoff flow, fallout, and ground water to a surface-water system) and subsequent mixing.

Effects of water quality (e.g., PH, water temperature, salinity) and sediment characteristics (e.g., clay minerals) are taken into account through changes in the distribution (or partition) coefficient, $k_{d j}$, and transfer rate, $k_{j}$, as shown in the last term of Equation (42).

However, similar to the sediment-transport equation discussed above, the net flux of dissolved contaminant through vertical and lateral boundaries are incorporated in the governing equation as sink/source and decay terms in this model, rather than treated as boundary conditions [Equations (45) through (47)], as shown below:

$$
\begin{aligned}
\frac{\partial G_{W}}{\partial t} & +\frac{\partial}{\partial R}\left(U G_{W}\right)+\frac{\partial}{\partial X}\left(W G_{w}\right)+\frac{\partial}{\partial Z}\left(V G_{W}\right)=\frac{\partial}{\partial R}\left(\varepsilon_{R} \frac{\partial G_{W}}{\partial R}\right)+\left(\varepsilon_{X} \frac{\partial G_{W}}{\partial X}\right)+\frac{\partial}{\partial Z}\left(\varepsilon_{Z} \frac{\partial G_{W}}{\partial Z}\right) \\
& -\left[\lambda+\sum_{j} K_{j} C_{j} K_{d j}-\frac{1}{\Delta Z} \sum_{j} \gamma_{j}(1-P O R) D_{j} K_{b j} K_{d j}\right] G_{W} \\
& +\left[\sum_{j} K_{j} G_{j}+\frac{Q_{w}}{\Delta X}-\frac{1}{\Delta Z} \sum_{j} \gamma_{j}(1-P O R) D_{j} K_{b j} G_{B j}\right]
\end{aligned}
$$

Boundary conditions are

$$
\begin{aligned}
V G_{W}-\varepsilon & \frac{\partial G_{W}}{\partial Z}=0 & & \text { at } Z=h \\
\frac{\partial G_{W}}{\partial Z} & =0 & & \text { at } Z=0 \\
\frac{\partial G_{W}}{\partial X} & =0 & & \text { at } X=0 \\
\frac{\partial G_{W}}{\partial X} & =0 & & \text { at } X=B
\end{aligned}
$$


In addition to the previously defined symbols:

$D_{j}=$ diameter of $j^{\text {th }}$ sediment

$K_{b j}=$ transfer rate of contaminants with $j^{\text {th }}$ non-moving sediment in bed

$K_{d j}=$ distribution (or partition) coefficient between dissolved contaminant and particulate contaminant associated with $j^{\text {th }}$ sediment

$k_{j}=$ transfer rate of contaminant for $j^{\text {th }}$ sediment

$G_{B j}=$ particulate-contaminant concentration per unit weight of sediment in $j^{\text {th }}$ sediment size fraction in the bed

$G_{j}=$ particulate-contaminant concentration associated with $j^{\text {th }}$ sediment (weight of contaminant or radionuclide activity per unit volume of water)

$G_{W}=$ dissolved-contaminant concentration (weight of contaminant or radionuclide activity per unit volume of water)

$G_{\text {wo }}=$ constant concentration of dissolved contaminant

$P O R=$ porosity of bed sediment

$Q_{W}=$ lateral influx of dissolved contaminant

$r_{j}=$ specific weight of $j^{\text {tn }}$ sediment

$\lambda=$ radionuclide decay or, chemical and biological degradation rates of contaminant

Note that the particulate-contaminant concentration associated with sediment in a water column, $G_{j}$, in Equation (66), is expressed in terms of the contaminant weight or radionuclide activity per unit volume of water, instead of per unit weight of sediment, used in Equations (42), (45), (46) and (47). Particulate-Contaminant Transport

The migration (transport, deposition, and erosion) and fate of contaminants (e.g., radionuclides) attached to sediments are solved separately for those adsorbed by each sediment-size fraction of cohesive and noncohesive 
sediments. Three-dimensional distributions of particulate contaminant adsorbed by the $j^{\text {th }}$ sediment can be obtained by solving Equations (52) through (55). These equations include mechanisms of:

1. advection and dispersion of particulate contaminant

2. adsorption (uptake) of dissolved contaminant by sediments or desorption from sediments into water

3. radionuclide decay, or chemical and biological degradiation of contaminant.

4. deposition of particulate contaminant on river bed or erosion from the bed

5. contaminant contributions from point and nonpoint sources to the system (e.g., contaminant contributions from wastewater discharges, overland runoff flow, fallout, and ground water to a surface water system) and subsequent mixing.

Similar to the sediment and dissolved-contaminant transport equations, the net flux of particulate contaminant through vertical and lateral boundaries are incorporated in the governing equation as sink/source and decay terms in this model, rather than treated as boundary conditions [Equations (53) through (55)], as shown in Equation (67).

The governing equation of particulate-contaminant transport associated with $j^{\text {th }}$ sediment is:

$$
\begin{aligned}
\frac{\partial G_{j}}{\partial t} & +\frac{\partial}{\partial R}\left(U G_{j}\right)+\frac{\partial}{\partial X}\left(W G_{j}\right)+\frac{\partial}{\partial Z}\left\{\left(V-V_{S j}\right) G_{j}\right\}=\frac{\partial}{\partial R}\left(\varepsilon_{R} \frac{\partial G_{j}}{\partial R}\right) \\
& +\frac{\partial}{\partial X}\left(\varepsilon_{X} \frac{\partial G_{j}}{\partial X}\right)+\frac{\partial}{\partial Z}\left(\varepsilon_{Z} \frac{\partial G_{j}}{\partial Z}\right)-\left(\lambda+K_{j}+\frac{S_{D j}}{\Delta Z}\right) G_{j} \\
& +\left(K_{j} K_{d j} C_{j} G_{W}+\frac{G_{B j} S_{R j}}{\Delta Z}+\frac{Q_{j}}{\Delta X}\right)
\end{aligned}
$$


Boundary conditions are:

$$
\begin{aligned}
\left(V-V_{s j}\right) G_{j}-\varepsilon_{Z} \frac{\partial G_{j}}{\partial Z}=0 & \text { at } Z=h \\
(1-\gamma) V_{s j} G_{j}+\varepsilon_{Z} \frac{\partial G_{j}}{\partial Z}=0 & \text { at } Z=0 \\
\frac{\partial G_{j}}{\partial X}=0 & \text { at } X=0 \\
\frac{\partial G_{j}}{\partial X}=0 & \text { at } X=B
\end{aligned}
$$

where

$\begin{aligned} Q_{j}= & \text { lateral influx of particulate contaminant associated with } j^{\text {th }} \\ & \text { sediment. }\end{aligned}$

Note that the particulate-contaminant concentration associated with the $j^{\text {th }}$ sediment in a water column, $G_{j}$, in Equation (67) has a unit of the contaminant weight or radioactivity per unit volume of water, instead of per unit weight of sediment used in Equations (52) through (55).

The computation scheme being used for these governing equations is a finite-difference technique.

\subsection{PRELIMINARY TESTING OF THE MODEL}

Several computer runs were made to examine the usable-aspect ratio ( $r$ atio of length to width to height) of each computational cell. Usable-aspect ratios were examined by computing the flow pattern in a rectangular waterbody with the upstream velocity of $2.0 \mathrm{ft} / \mathrm{sec}$, as shown in Figure 7 . The first case has an aspect ratio of 1 (vertical direction 2 ): 10 (lateral direction $X$ ): 100 (longitudinal direction $R$ ). The variation of computed longitudinal velocities (U) along $Z=5.5 \mathrm{ft}$ and $X=25 \mathrm{ft}$ at $R=100 \mathrm{ft}, 200 \mathrm{ft}, 300 \mathrm{ft}, 400 \mathrm{ft}$, and $500 \mathrm{ft}$ are shown in Figure 8 . The vertical variation of computed longitudinal 


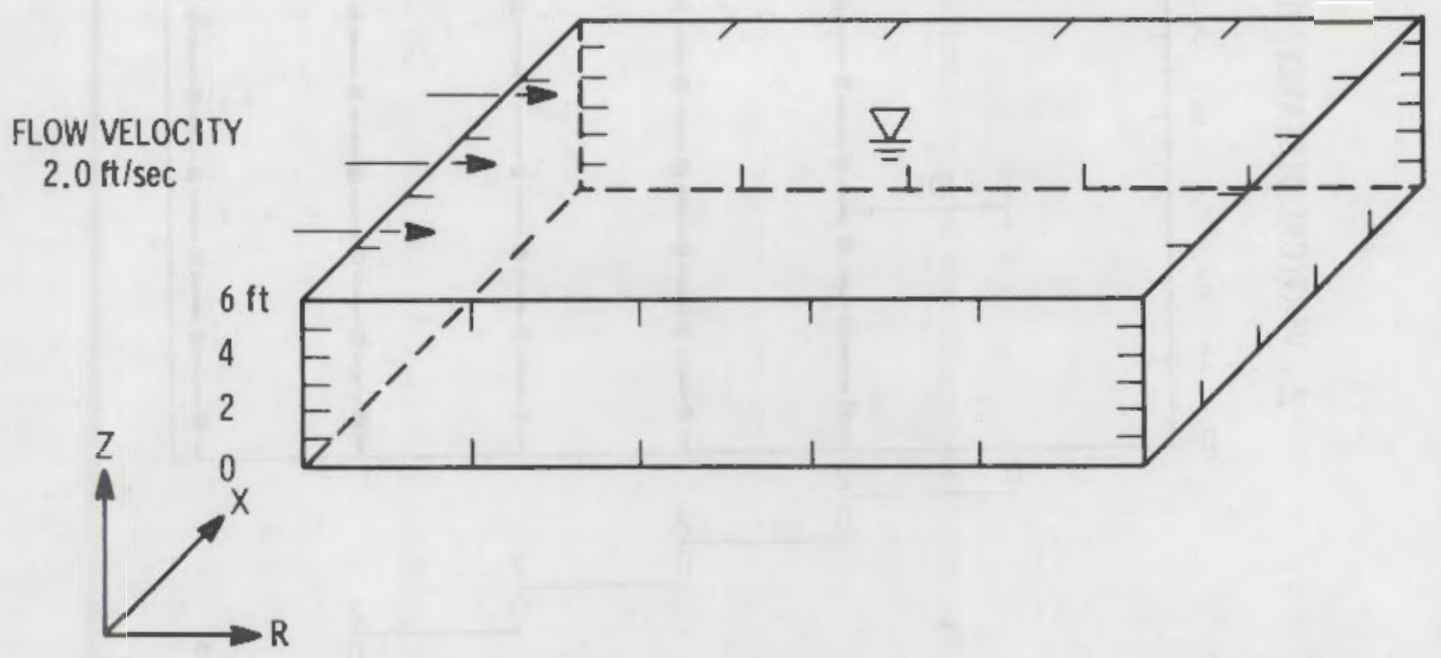

FIGURE 7. Rectangular Waterpody Used for the Examination of the Aspect Ratio

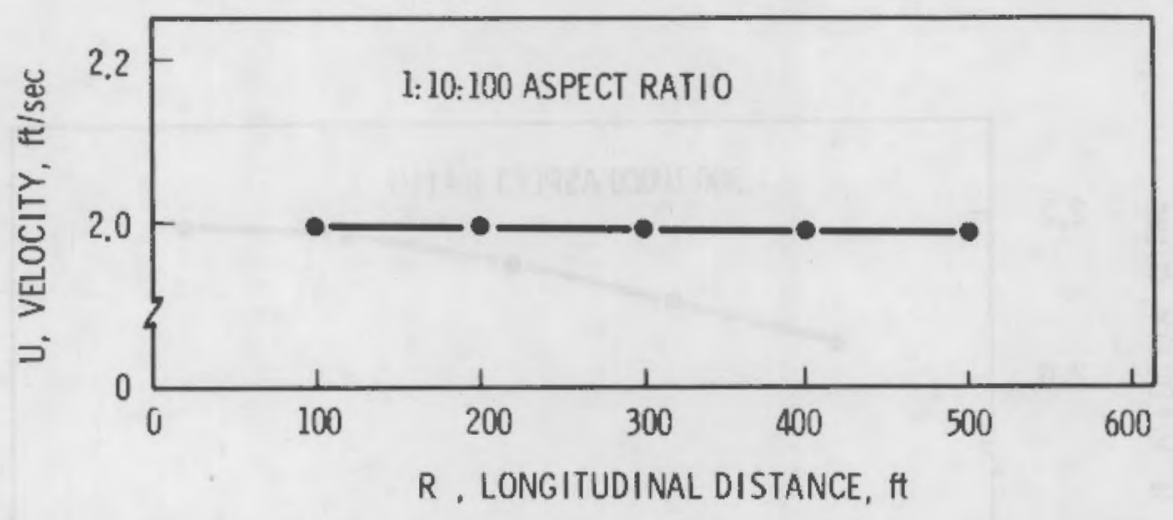

FIGURE 8. Variation of Longitudinal (Downstream) Velocities Along $Z=5.5 \mathrm{ft}$ and $X=25 \mathrm{ft}$

velocities along $X=25 \mathrm{ft}$ at these five locations are shown in Figure 9. These figures indicate that distributions of longitudinal velocities are almost uniform both longitudinally and vertically.

The second case has an aspect ratio of 1 ( $Z$ direction):300 ( $X$ direction): 10,000 ( $R$ direction). Computed longitudinal velocities $(U)$ at $R=10,000 \mathrm{ft}$, $20,000 \mathrm{ft}, 30,000 \mathrm{ft}, 40,000 \mathrm{ft}$, and 50,000 ft are shown in Figures 10 and 11. Figure 11 indicates that vertical velocity distributions are no longer uniform 


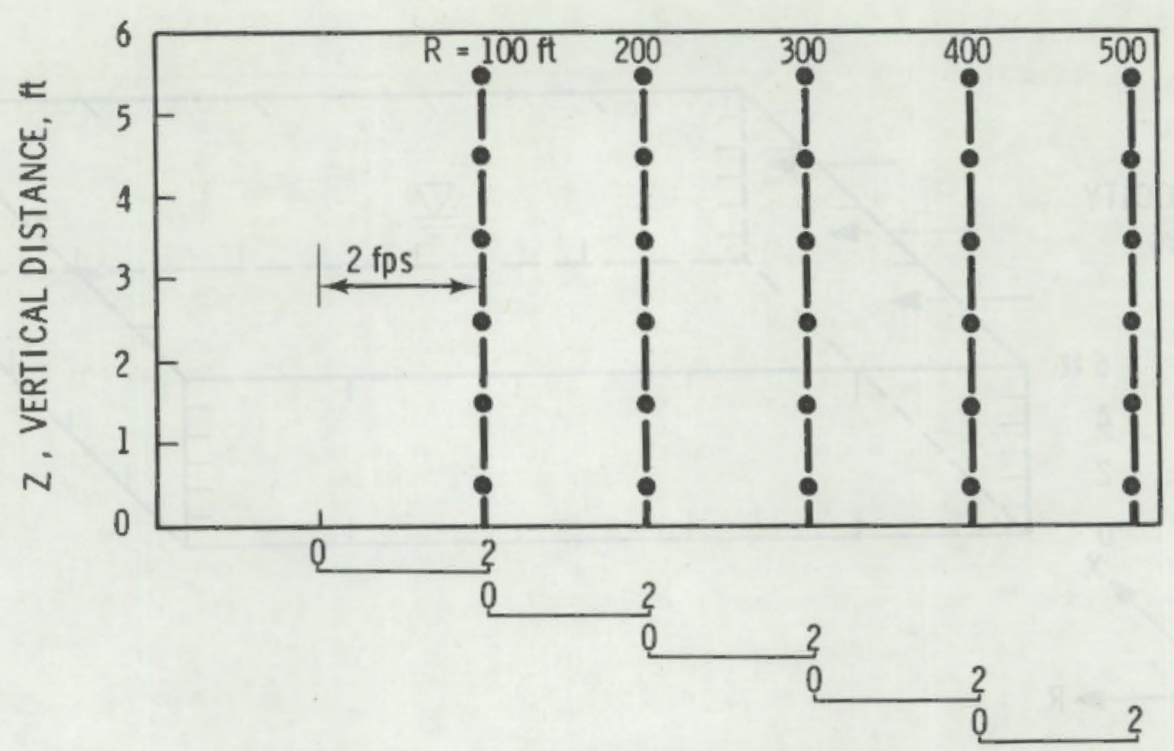

U, VELOCITY, $\mathrm{ft} / \mathrm{sec}$

FIGURE 9. Vertical Variation of Longitudinal (Downstream) Velocities Along $x=25 \mathrm{ft}$

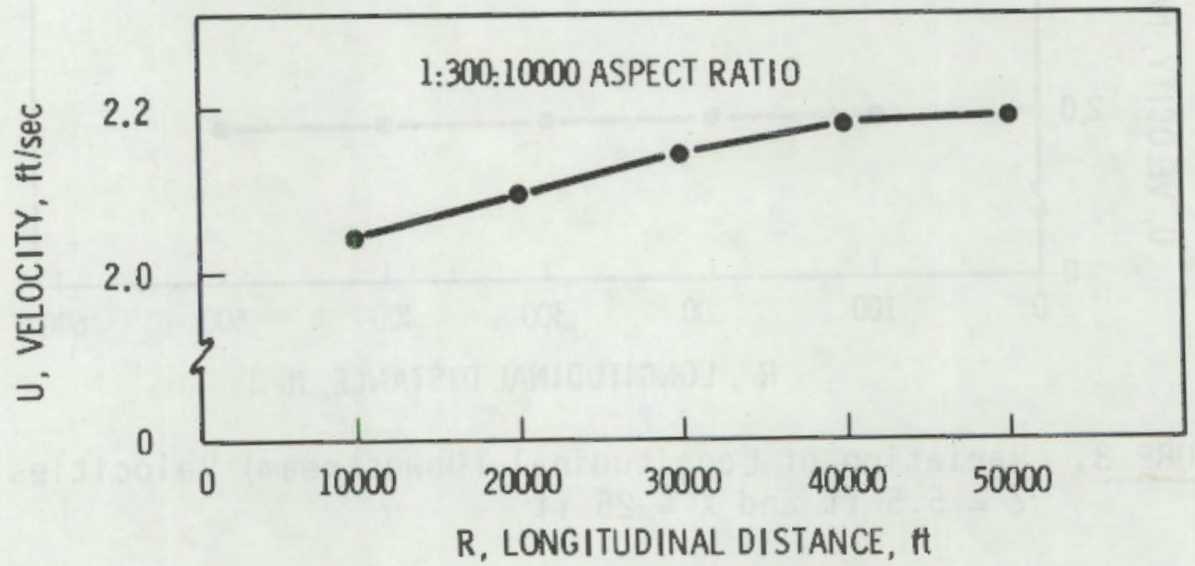

FIGURE 10. Variation of Longitudinal (Downstream) Velocities Along $Z=5.5 \mathrm{ft}$ and $X=750 \mathrm{ft}$

because the boundary layer formed along the bottom surface is reducing the velocity near the bottom and consequently increasing the velocity near the water surface. The further the longitudinal distance, the more this trend shows, as indicated in Figure 10. These two cases demonstrate that the threedimensional model can handle very large aspect ratios of computational cells, which is essential if the model is to have a practical usage to estuarine radionuclide modeling. 


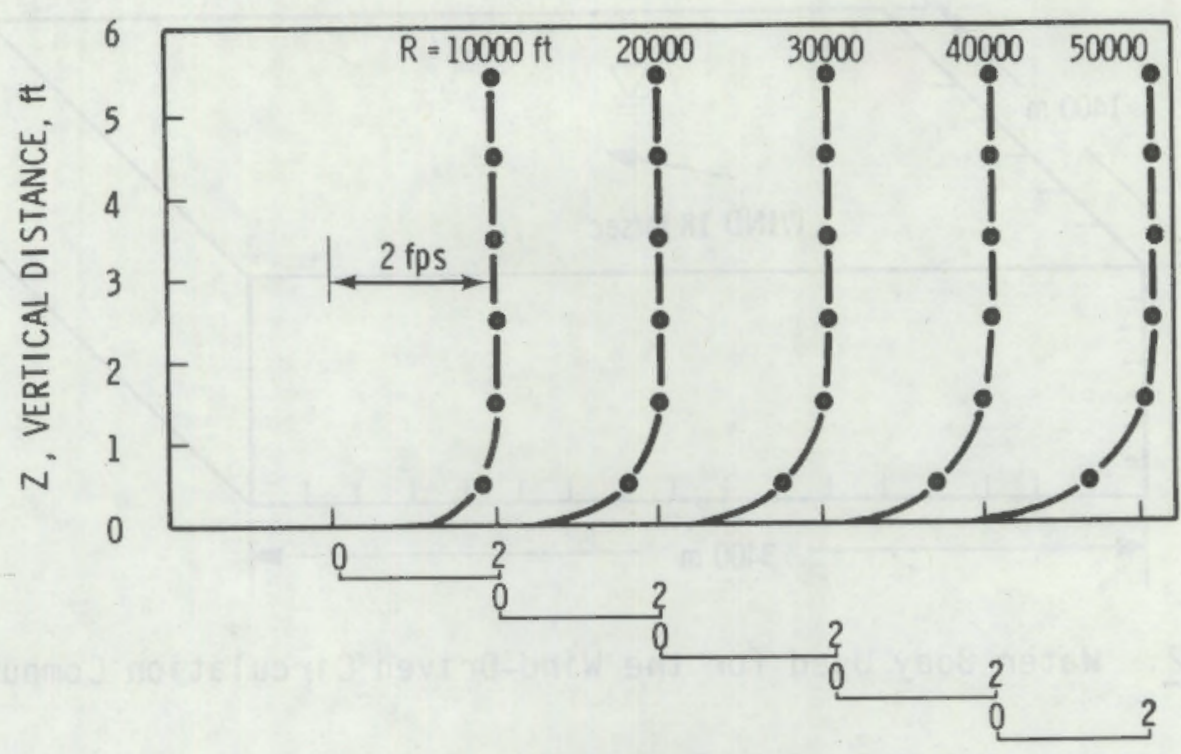

U, VELOCITY, ft/sec

FIGURE 11. Vertical Variation of Longitudinal (Downstream) Velocities Along $X=750 \mathrm{ft}$

The next test was to simulate wind-driven circulations in a $3400 \mathrm{~m}-1 \mathrm{ong}$, $1400-m$ wide and $7-m$ deep rectangular water basin with a diagonal wind of $18 \mathrm{~m} / \mathrm{sec}$ blowing on the water surface, as shown in Figure 12. This case was selected as a test case because Leendertse, Alexander and Liu (1973) reported their computation results by using their quasi-three-dimensional model (a vertically layered model). In their application, the basin was divided into vertical layers of equal thickness (layers one through seven, from the water surface to the basin bed). Although Leendertse, Alexander and Liu allowed the water-surface elevation to be changed for their application, the present application imposed the fixed water-surface elevation. Although our model currently includes a mechanism for the water-surface elevation change, the fixed water surface elevation condition was imposed in this case to simplify the model application. Computed results by our three-dimensional model is shown in Figure 13 at the time of $375 \mathrm{sec}$. Figure $13 \mathrm{a}$ indicates the flow pattern on the vertical section along the center $(x=700 \mathrm{~m})$, while Figures $13 \mathrm{~b}$ through $13 \mathrm{j}$ show the horizontal patterns at seven different elevations. These figures indicate a large basin-wide circulation induced by the wind. Computed results by the Leendertse's model are shown in Figure 14 . Computed results in seven vertical 


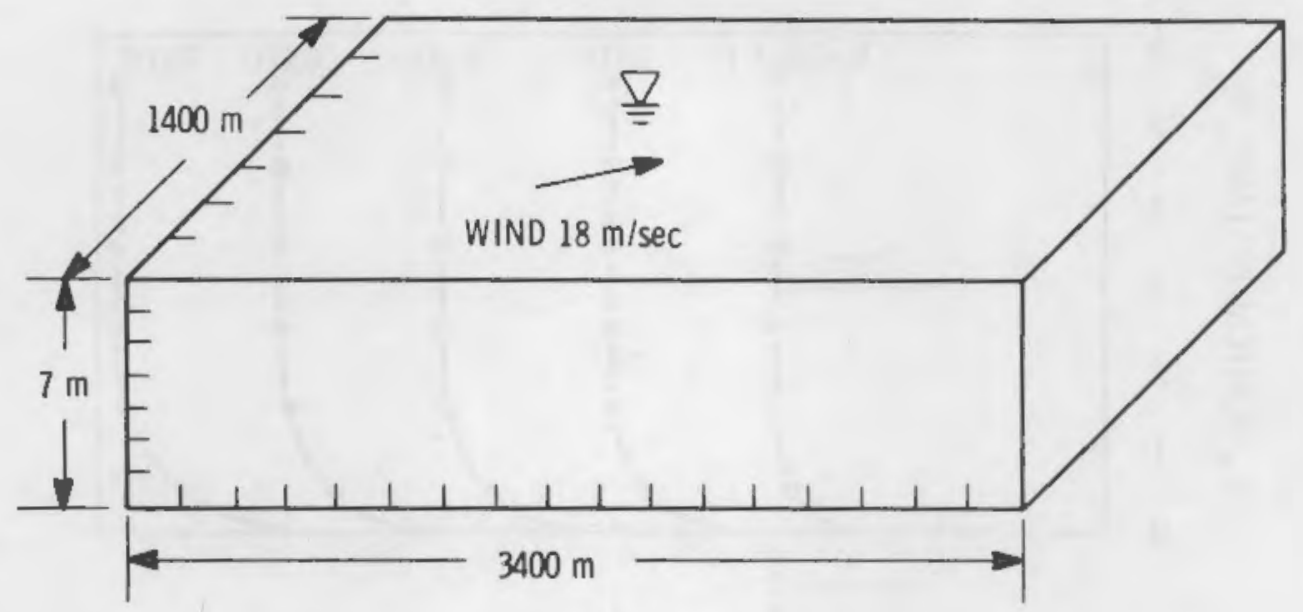

FIGURE 12. Water Body Used for the Wind-Driven Circulation Computation

layers in Figure 14 correspond to those at seven depths in Figure 13 . General flow patterns computed by these two models agreed well. Some discrepancy on the flow pattern, however, appears near the right and left hand corners of the water surface (Figures $13 a$ and $14 a$ ). This is mainly due to the different conditions imposed to the water surface, i.e., the application by Leendertse, Alexander and Liu (1973) allows the water-surface elevation to be changed, while the current application did not.

\subsection{MOOEL APPLICATION}

Availability of field data required for the radionuclide transport modeling in a United States' estuary was examined through literature review. Because of the best availability of the required data, the Hudson River estuary was selected as the modeling site. Figure 15 shows the Hudson River estuary. Information on the channel geometry and bathymetry, flow, salinity distributions, sediment distributions, and radionuclide distributions in the Hudson River estuary has been collected through literature survey. 


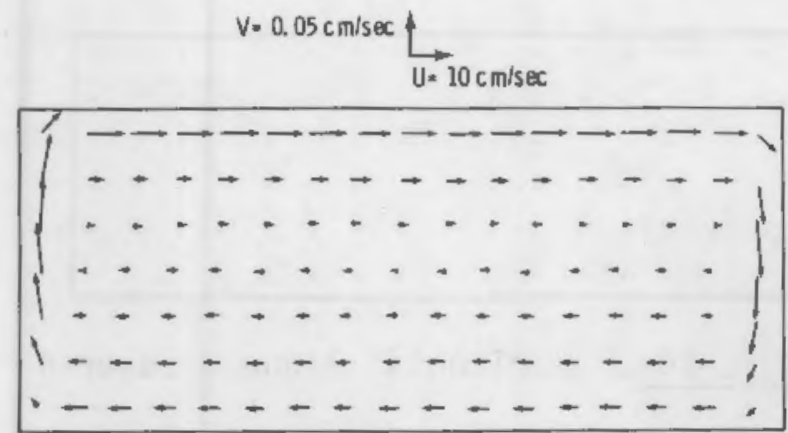

FIGURE 13a. At $375 \mathrm{sec}$ Vertical Section Along the Center

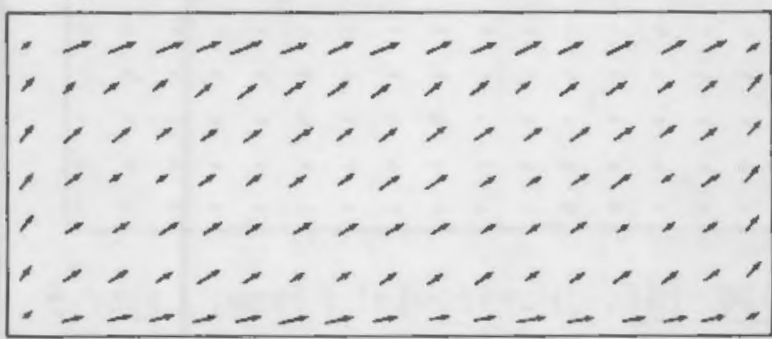

FIGURE 13b. Horizontal Section: Top $(6.5 \mathrm{~m})$

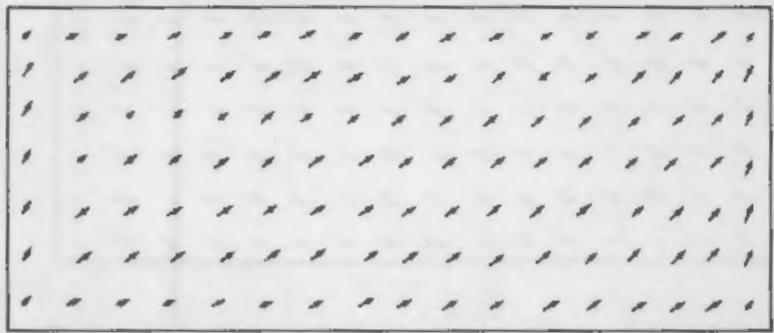

FIGURE 13c. Horizontal Section: $5.5 \mathrm{~m}$

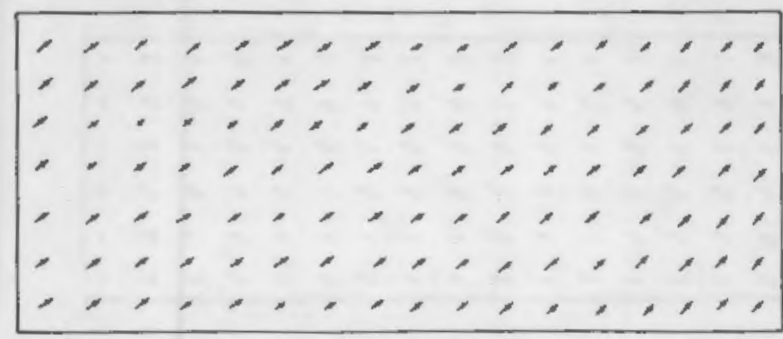

FIGURE 13d. Horizontal Section: $4.5 \mathrm{~m}$
$W=10 \mathrm{~cm} / \mathrm{sec}$

$\mathrm{U}=10 \mathrm{~cm} / \mathrm{sec}$

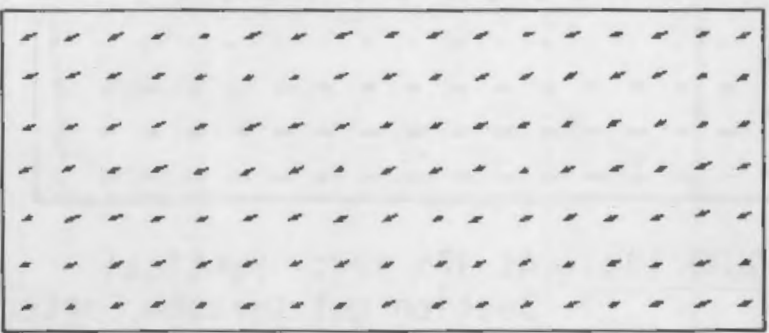

FIGURE 13e. Horizontal Section: $3.5 \mathrm{~m}$

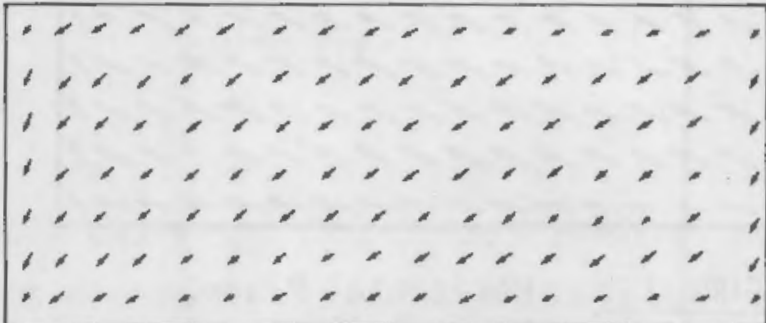

FIGURE 13f. Horizontal Section: $2.5 \mathrm{~m}$

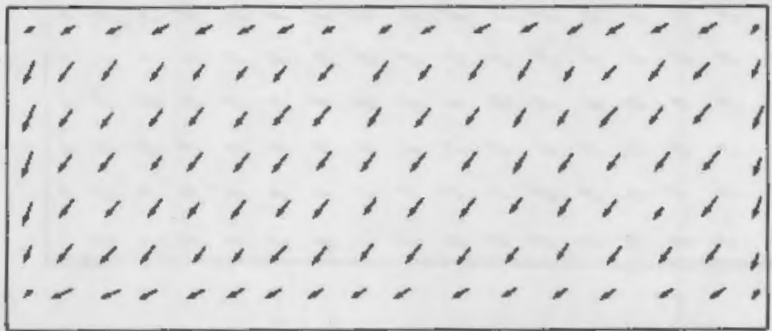

FIGURE 13i. Horizontal Section: $1.5 \mathrm{~m}$

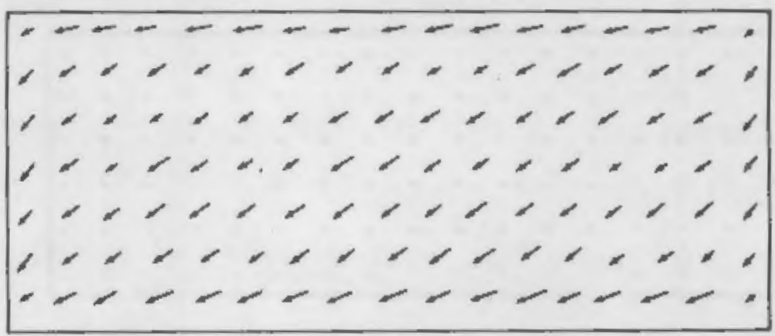

FIGURE $13 \mathrm{j}$. Horizontal Section: Bottom $(0.5 \mathrm{~m})$

FIGURE 13. Predicted Velocity Distributions in a Cross-Section and in Seven Horizontal Planes in a Wind-Driven Rectangular Basin at 375 Second of the Computation 


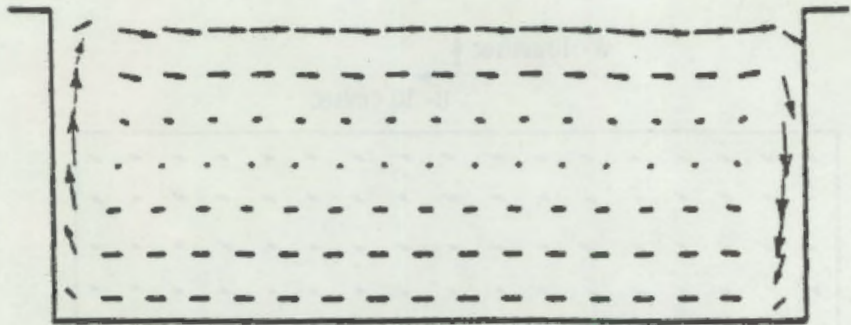

FIGURE 14a. At 375 sec: Vertical Section cut through Center

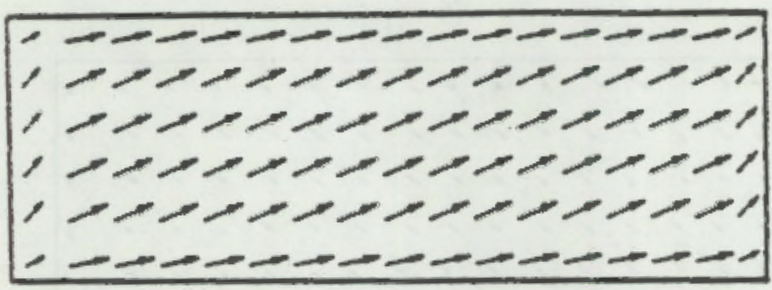

FIGURE 14b. Horizontal Plane, Layer 1 (Surface)

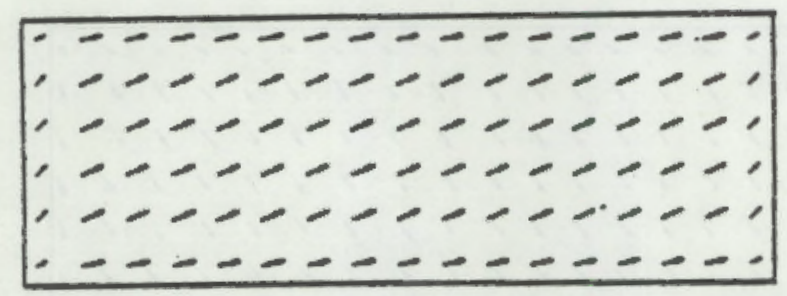

FIGURE 14C. Horizontal Plane, Layer 2
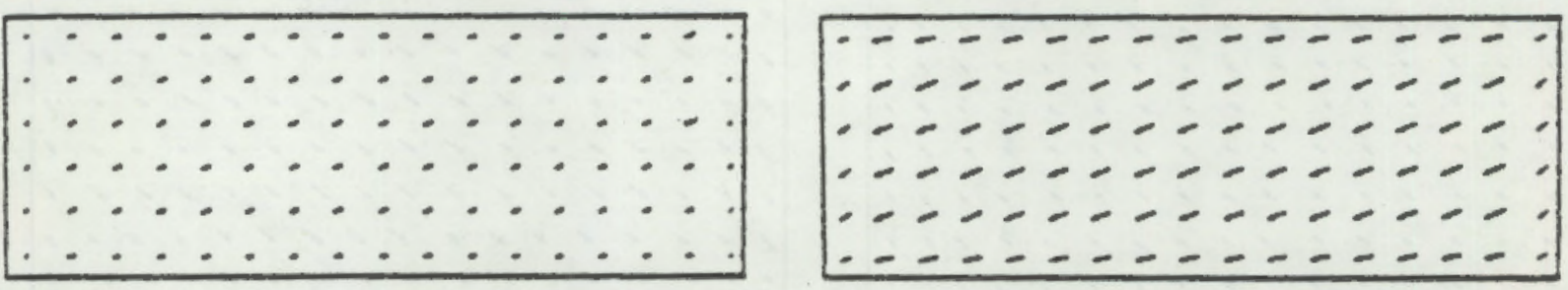

FIGURE 14d. Horizontal Plane, Layer 3 FIGURE 14j. Horizontal Plane, Layer 7 (Bottom)

FIGURE 14. Velocity Distribution in a Cross-Section and in Seven Horizontal Layers of a Wind-Driven Rectangular 8 asin at 375 Second of the Computation by the Leendertse Model (1973). Scales of corresponding velocities shown in Figures 13 and 14 are the same. 


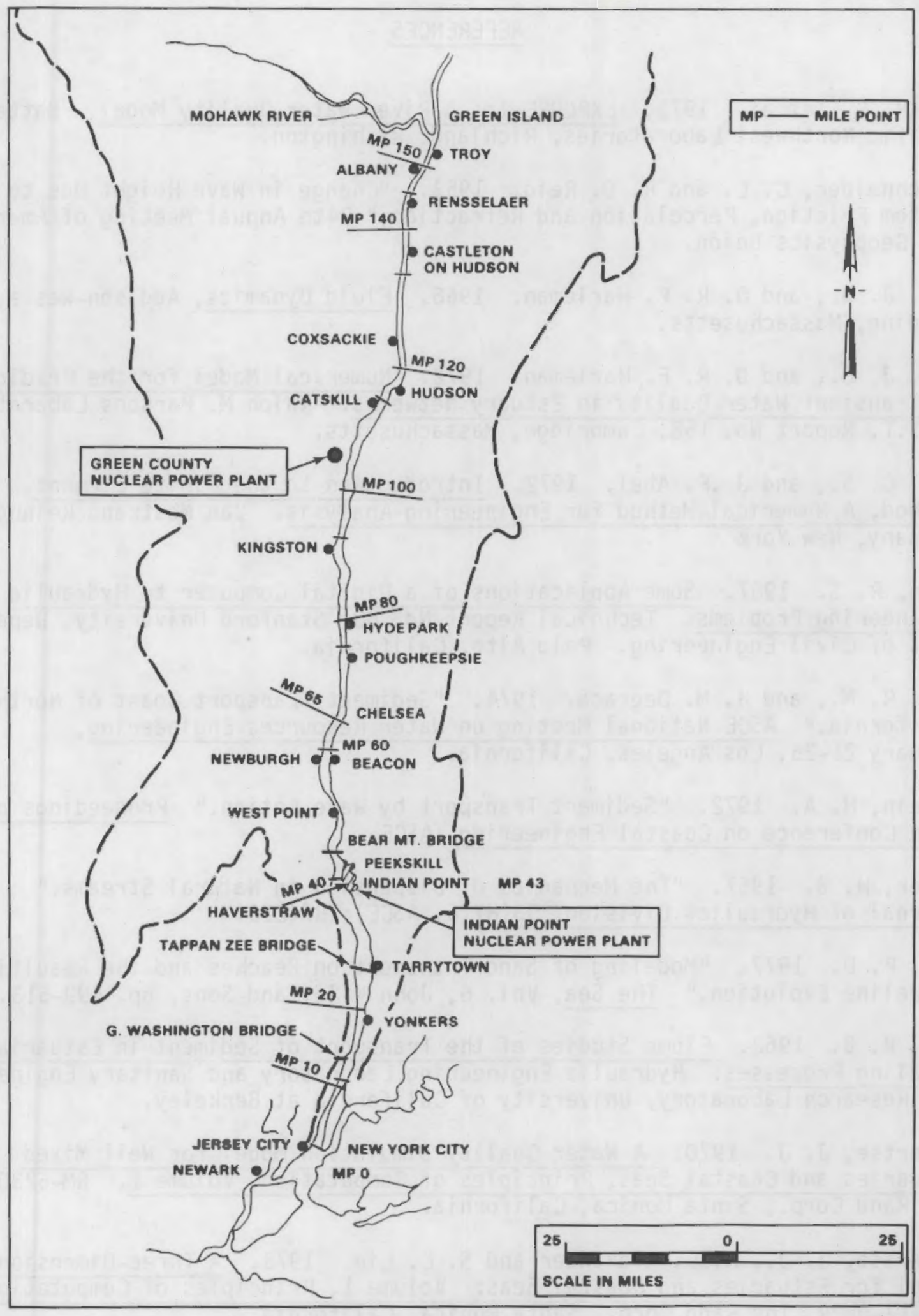

FIGURE 15. Hudson River Estuary 


\section{REFERENCES}

Baca, R. G., et al. 1973. EXPLORE-I: A River Water Quality Model. Battelle, Pacific Northwest Laboratories, Richland, Washington.

Bretschneider, C. L. and R. 0. Reid. 1953. "Change in Wave Height Due to Bottom Friction, Percolation and Refraction," 34 th Annual Meeting of American Geophysics Union.

Daily, J. W., and D. R. F. Harleman. 1966. Fluid Dynamics, Addison-Wesley, Reading, Massachusetts.

Daily, J. E., and D. R. F. Harleman. 1972. Numerical Model for the Prediction of Transient Water Quality in Estuary Networks. RaTph M. Parsons Laboratory, M.I.T. Report No. 158, Cambridge, Massachusetts.

Desai, C. S., and J .F. Abe1. 1972. Introduction to the Finite Element Method, A Numerical Method for Engineering Analysis. Van Nostrand Reinhold Company, New York

Dobson, R. S. 1967. Some Applications of a Digital Computer to Hydraulic Engineering Problems. Technical Report No. 80, Stanford University, Department of Civil Engineering. Palo Alto, California.

Ecker, R. M., and H. M. Degraca. 1974. "Sediment Transport Coast of Northern California." ASCE National Meeting on Water Resources Engineering, January 21-25, Los Angeles, California.

Einstein, H. A. 1972. "Sediment Transport by Wave Action." Proceedings of 13 th Conference on Coastal Engineering, ASCE.

Fischer, H. B. 1967. "The Mechanics of Dispersion in Natural Streams." Journal of Hydraulics Division. 93(HY,6, ASCE):187-216.

Komar, P. D. 1977. "Modeling of Sand Transport on Beaches and the Resulting Shoreline Evolution." The Sea, Vol. 6, John Wiley and Sons, pp. 499-513.

Krone, R. B. 1962. Flume Studies of the Transport of Sediment in Estuarial Shoaling Processes. Hydraulic Engineering Laboratory and Sanitary Engineering Research Laboratory, University of California at Berkeley.

Leendertse, J. J. 1970. A Water Quality Simulation Model for Well Mixed Estuaries and Coastal Seas, Principles of Computation, Volume I. RM-6230-RC, The Rand Corp., Santa Monica, California.

Leendertse, J. J., R. C. Alexander and S. L. Liu. 1973. A Three-Dimensional Model for Estuaries and Coastal Seas: Volume 1, Principles of Computation. R-1417-OWRR, The Rand Corp., Santa Monica, California. 
Liang, S. S., and H. Wang. 1973. Sediment Transport in Random Waves. Technical Report No. 26, University of Delaware, College of Marine Studies.

Onishi, Y. 1977. Mathematical Simulation of Sediment and Radionuclide Transport in the Columbia River. BNWL-2228, Battelle, Pacific Nor thwest Laboratories, Richland, Wasnington.

Onishi, Y., and S. E. Wise. 1978. "Mathematical Modeling of Sediment and Contaminant Transport in the James River Estuary," Proceedings of 27 th Annual ASCE Hydraulic Division Speciality Conference on Verification of Mathematical and Physical Models in Hydraulic Engineering. College Park, Maryland, August 9-11, pp. 303-310.

Onishi, Y., and S. E. Wise. 1979. "F inite Element Model for Sediment and Toxic Contaminant Transport in Streams." Proceedings of Hydraulics and Energy Divisions Specialty Conference of ASCE on "Conservation and UtiTization of water and Energy Resources". San Francisco, California, pp. 144-150.

Onishi, Y., E. M. Arnold and D. W. Mayer. 1979. Modified Finite Element Transport Model, FETRA, for Sediment and Radionuclide Migration in Open Coastal waters. NUREG/CR-1026. PNL-3114, Pacific Northwest Laboraotry, Richland, Washington.*

Onishi, Y., R. J. Serne, E. M. Arnold, C. W. Cowan and F. L. Thompson. 1980a. Critical Review: Radionuclide Transport, Sediment Transport, and Water Quality Mathematical Modeling: and Radionuclide Adsorption/Desorption Mechanisms. NUREG/CR-1322, PNL-2901, Pacific Nor thwest Laboratory, Richland, Washington.*

Onishi, Y., D. L. Schreiber and R. B. Code11. 1980b. "Mathematical Simulation of Sediment and Radionuclide Transport in the Clinch River, Tennessee." In Contaminants and Sediments, Vol. 1, ed. R. A. Baker, pp. 393-406. Ann Arbor Science Publisher, Inc., Ann Arbor, Michigan.

Partheniades, E. 1962. A Study of Erosion and Deposition of Cohesive Soils in Salt Water, Ph.0. Thesis, University of California at Berkeley.

Sayre, W. W. 1966. "Dispersion of Silt Particles in Open Channel Flow." J. of Hydraulic Division, ASCE, Vol. 92, No., HY3, Proc. Paper 6579, May 1966, pp. 1009-1038.

Schlichting, H. 1968. Boundary-Layer Theory. MCGraw Hill Book Co., New York.

Sverdrup, H. U., and W. H. Munk. 1947. Wind, Sea and Swe 11; Theory of Relationships for Forecasting. Pub. No. 601, U.S. Navy Hydrographic Office, Washington, DC.

U.S. Army Corps of Engineers, Beach Erosion Board. 1962. Waves in Inland Reservoirs, Summary Report on Civil Works Investigation Projects CW-164 and CW-165, Tech. Memo No. 132 . 
U.S. Army Corps of Engineers. Coastal Engineering Research Center. 1956. Shore Protection, Planning and Design, Technical Report No. 4, Third Edition.

U.S. Army Corps of Engineers, Coastal Engineering Research Center. 1973. Shore Protection Manual, Vol. 3.

Vanoni, V. A. 1975. Sedimentation Engineering. Prepared by the ASCE Task Committee for the Preparation of the Manual on Sedimentation of the Sedimentation Committee of the Hydraulics Division, New York, NY.

Yotsukura, N., and W. W. Sayre. 1976. "Transverse Mixing in Natural Channels." Water Resources Research. 12(4):695-704.

*Available for purchase from the NRC/GPO Sales Program, U.S. Nuclear Regulatory Commission, Washington, DC 20555, and/or the National Technical Information Service, Springfield, VA 22161. 


\section{ACKNOWLEDGMENTS}

The authors wish to express their gratitude to D. W. Mayer for his assistance to this project, which included data collection for the Hudson River estuary through literature survey. The authors are also grateful to E. M. Arnold for his assistance in the modification of the sediment and contaminant transport model, FETRA. 
. 
NUREG/CR-1034

PNL-3120

\section{DISTRIBUTION}

No. of

Copies

OFFSITE

A. A. Churm

DOE Patent Division

9800 South Case Avenue

Argonne, IL 60439

265 U.S. Nuclear Regulatory Commission

Division of Technical Information and Document Control

7920 Norfolk Avenue

Bethesda, MD 20014

2 DOE Technical Information Center

C. V. Alenso

U.S. Department of Agriculture Sedimentation Laboratory

Southern Region

Agricultural Research Center

P.0. Box 1157

Oxford, MI 38655

J. Lun in

U.S. Department of Agriculture

Science and Education Administration

Agriculture Research

National Program Staff

Beltsville, MD 20705

H. Pionke

U.S. Department of Agriculture Northeast Watershed Research Laboratory

110 Research Building A

Pennsylvania State University

University Park, PA 10802
No. of

Copies

R D. Wauchope

U.S. Department of Agriculture

Stoneville, MS 38776

R. A. Baker

U.S. Geological Survey

National Space Technology

Laboratories

NSTL Station, MS 39529

J. J. Cassidy, Director

Water Research Center

Washington State University

Pullman, WA 99164

J. J. Connor

Deptartment of Civil Engineering

Massachusetts Institute of Technology

Cambridge, MA 02139

D. N. Edgington

Center of Great Lake Studies

University of Wisconsin

P.0. Box 413

Milwaukee, WI 53201

H. B. Fischer

Department of Civil

Engineering

University of California

at Berkeley

Berkeley, CA 94720

E. F. Gloyna

College of Engineering

University of Texas at Aust in

Austin, TX 78705 
No. of

Copies

E. R. Holley

Department of $\mathrm{C}$ ivil Engineering

University of Illinois

Urbana, I1linois 61801

Irving Joseph

Bechtel Corporation

50 Beale Street

San Francisco, CA 94105

G. H. Jirka

Department of Environmental

Engineering

Cornell University

Ithaca, NY 14850

J. F. Kennedy

Institute of Hydraulic Research

University of I owa

I owa City, Iowa 52241

R. B. Krone

Department of Civil Engineering

University of California at Davis

Davis, CA 95616

F. 0. Hoffman

Oak Ridge National Laboratory

oak Ridge, TN 37830

C. A. Little

Health and Safety Research Division

Oak Ridge National Laboratory P.0. Box $X$

Oak Ridge, TN 37830

G. T. Yeh

Environmental Science Division

Oak Ridge National

Laboratory

Oak Ridge, TN 37830
No. of

Copies

E. Partheniades

Department of Engineering Science

University of Florida

Gainesville, Florida 32611

\section{A. J. Policastro}

Argonne National Laboratory

Argonne, IL 60439

J. C. Rodgers

Mail Stop 495

Los Alamos Scientific Laboratory

P.0. Box 1663

Los Alamos, NM 87545

Dr. P. J. Ryan

Bechtel Corporation

50 Beale Street

San Francisco, CA 94105

D. L. Schreiber

P.0. Box $1087, c / 0$ The Colony

Coeur d'Alene, ID 83814

H. G. Stefan

Department of Civil and

Mineral Engineering

University of Minnesota

Minneapolis, MN 55455

J. Steger

Health Division

LS-G, Mail Stop 495

LoS Alamos Scientific Laboratory

P.0. $80 \times 1663$

Los Alamos, NM 87545

W. J. Garrett

U.S. Corps of Engineers

New Orleans District

P.0. Box 60261

New Or leans, LA 70160

W. McAnally

U.S. Corps of Engineers

U.S. Army Engineering Waterways Experiment Station

Vicksburg, MS 39180 
W. A. Thomas

U.S. Corps of Engineers

U.S. Army Engineering Waterways Experiment Station

Vicksburg, MS 39180

B. R. Wink ley

U.S. Corps of Engineers

Vicksburg District

Vicksburg, MS 39180

R. B. Ambrose

U.S. Environmental Protection Agency

Environmental Research Laboratory

Athens, GA 30603

J. W. Falco

U.S. Environmental Protection Agency

Environmental Research Laboratory

Athens, GA 30603

L. A. Mulkey

U.S. Environmental Protection Agency

Environmental Research Laboratory

Athens, GA 30603

M. Shirazi

U.S. Environmental Protection Agency

Pacific Northwest Water Laboratory

200 S.W. 35 th Street

Corvallis, OR 97331

P. Datta

U.S. Environmental Protection Agency

Office of Pesticide Program

Washington, DC 20460
C. Delos

Monitoring and Data Support Division

U.S. Environmental Protection Agency

401 M. St. SW

Washington, DC 20460

R. Hague

Office of Research and Development

U.S. Environmental Protection Agency

401 M. St. SW

Washington, OC 20460

C. R. Horn

Monitoring and Data Support Division

U.S. Environmental Protection Agency

401 M. St. SW

Washington, DC 20460

P. C. McGrath

Office of Pesticide Programs

U.S. Environmental Protection Agency

401 M. St. SW

Washington, DC 20460

J. J. Reisa

Office of Toxic Substances

U.S. Environmental Protection Agency

401 M. St. Sw

Washington, DC 20460

A. Stern

Office of Toxic Substances

U.S. Environmental Protection Agency

401 M. St. SW

Washington, DC 20460 
No. of

Copies

W. Wood

Office of Toxic Substances

U.S. Environmental Protection Agency

401 M. St. SW

Washington, DC 20460

W. L. Richardson

U.S. Environmental Protection Agency

Large Lakes Research Station

9311 Groh Road

Grosse Isle, MI 48138

P. C. Benedict

U.S. Geological Survey

345 Middlefield Road

Menlo Park, CA 21201

K. Bencala

U.S. Geological Survey

MS/96

345 Middlefield Rd.

Men lo Park,CA 94025

W. W. Sayre

U.S. Geological Survey

Box 25046, MS413, DFC

Lakewood, C0 80225

N. Yotsukura

U.S. Geological Survey

Water Resources Division

National Center

12201 Sunrise Valley Dr.

Reston, VA 22092

W. Bevins

U.S. Nuclear Regulatory

Commission

Washington, DC 20555
No. of

Copies

\author{
R. B. Codell \\ U.S. Nuclear Regulatory \\ Commission \\ Washington, DC 20555 \\ E. Hawkins \\ U.S. Nuclear Regulatory \\ Commission \\ Washington, DC 20555 \\ P. R. Reed (5) \\ U.S. Nuclear Regulatory \\ Commission \\ Washington, DC 20555 \\ F. Swanberg \\ U.S. Nuclear Regulatory \\ Commission \\ Washington, DC 20555
}

G. Zweig

322 Warren Hall

School of Public Health

University of California

Berkeley, CA 94720

J. J. Leendertse

RAND Corp.

Santa Monica, CA 90406

\section{ONSITE}

50 Pacific Northwest Laboratory

S. M. Brown

D. B. Cearlock

Y. Onishi (24)

A. M. Sutey

W. L. Templeton

D.S. Trent (5)

Technical Information (5)

Publishing Coordination BE (2)

Water and $L$ and Resources

Library (10) 


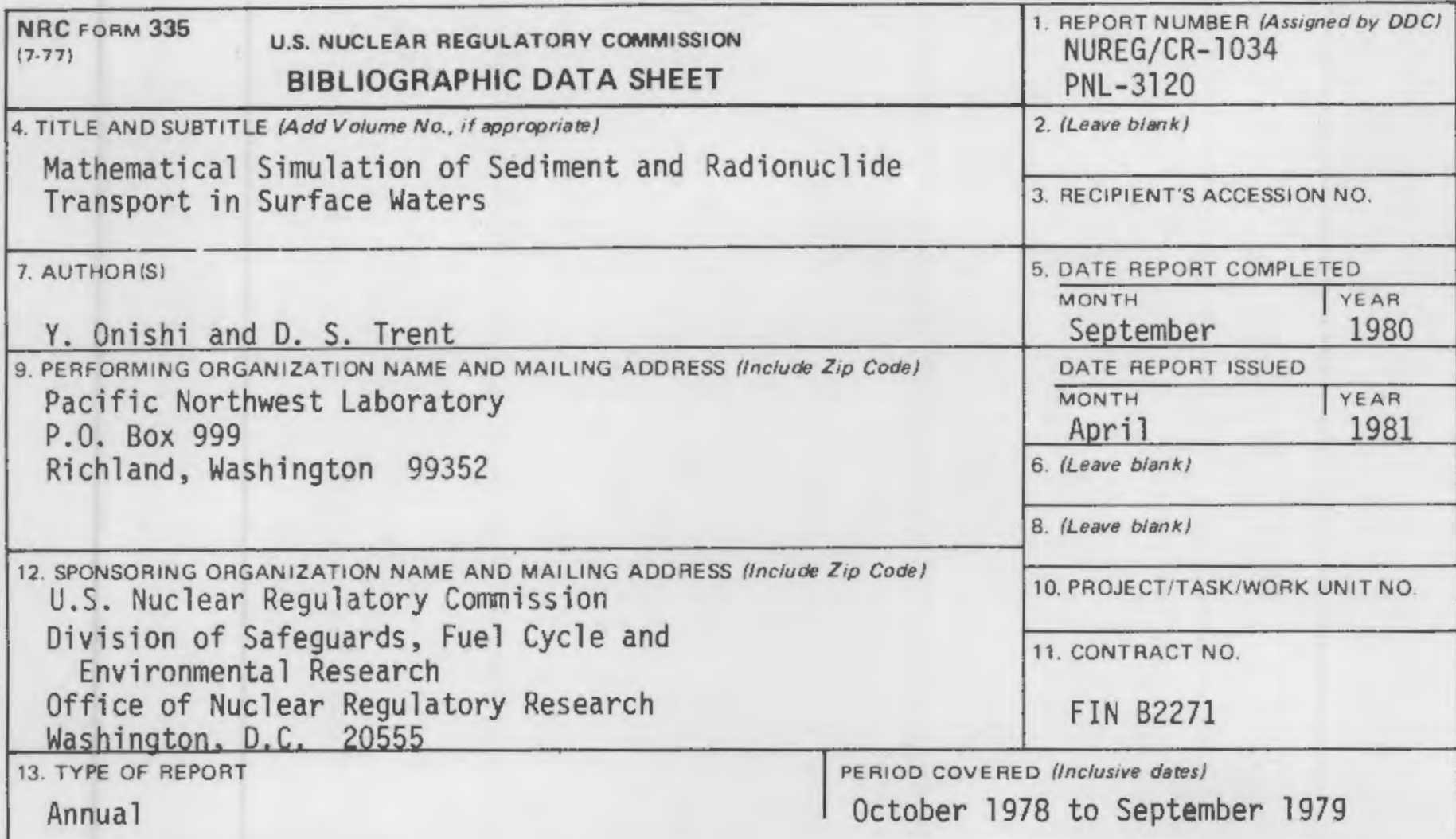

15. SUPPLEMENTARY NOTES

14. (Leave blank)

16. ABSTRACT (200 words or less) The study objective of "The Mathematical Simulation of Sediment and Contaminant Transport in Surface Waters" is to synthesize and test radionuclide transport models capable of realistically assessing radionuclide transport in various types of surface water bodies by including the sediment-radionuclide interactions. These interactions include radionuclide adsorption by sediment; desorption from sediment into water; and transport, deposition, and resuspension of sorbed radionuclides controlled by the sediment movements. During FY-1979, the modification of sediment and contaminant (radionuclide) transport model, FETRA, was completed to make it applicable to coastal waters. The model is an unsteady, two-dimensional (1ongitudinal and latera1) model that consists of three submodels (for sediment, dissolved-contaminant, and particulate-contaminant transport), coupled to include the sediment-contaminant interactions. In estuaries, flow phenomena and consequent sediment and radionuclide migration are often three-dimensional in nature mainiy because of nonuniform channel cross-sections, salinity intrusion, and laterial-flow circulation. Thus, an unsteady, three-dimensional radionuclide transport model for estuaries is also being synthesized by combining and modifying a PNL unsteady hydrothermal model and FETRA. These two radionuclide transport models for coastal waters and estuaries will be applied to actual sites to examine the validity of the codes.

17. KEY WORDS AND DOCUMENT ANALYSIS 17a. DESCRIPTORS

Radionuclide Transport,

Sediment Transport,

Mathematical Model,

Oceans,

Estuary, Surface Waters, Coastal Waters

17b. IDENTIFIERS/OPEN-ENDED TERMS

18. AVAILABILITY STATEMENT

Unlimited

\begin{tabular}{|c|c|}
\hline $\begin{array}{l}\text { 19. SECURITY CLASS (This report) } \\
\text { Unclass ified }\end{array}$ & 21. NO. OF PAGES \\
\hline 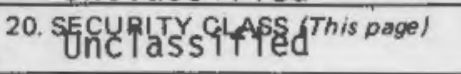 & $\begin{array}{l}\text { 22. PRICE } \\
\$\end{array}$ \\
\hline
\end{tabular}

NAC FORM 335 (7-77) 


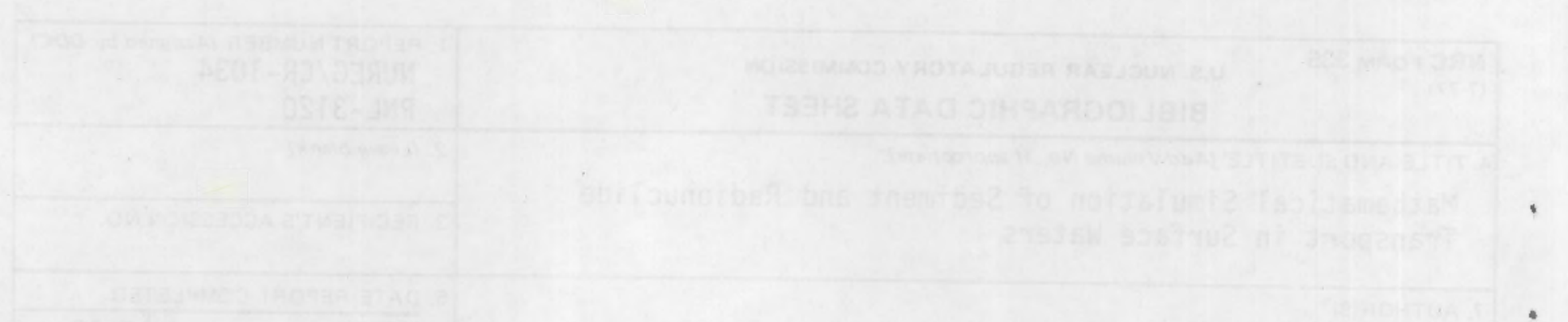


,

.

.

. 


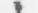

